\title{
Impact of Surface Forcing on Southern Hemisphere Atmospheric Blocking in the Australia-New Zealand Sector
}

\author{
CAROLINE C. UMmENHOFER* \\ Climate Change Research Centre, University of New South Wales, Sydney, New South Wales, Australia \\ Peter C. Mcintosh, Michael J. Pook, and James S. Risbey \\ Centre for Australian Weather and Climate Research, Hobart, Tasmania, Australia
}

(Manuscript received 9 December 2012, in final form 30 April 2013)

\begin{abstract}
Characteristics of atmospheric blocking in the Southern Hemisphere $(\mathrm{SH})$ are explored in atmospheric general circulation model (AGCM) simulations with the Community Atmosphere Model, version 3, with a particular focus on the Australia-New Zealand sector. Preferred locations of blocking in SH observations and the associated seasonal cycle are well represented in the AGCM simulations, but the observed magnitude of blocking is underestimated throughout the year, particularly in late winter and spring. This is related to overly zonal flow due to an enhanced meridional pressure gradient in the model, which results in a decreased amplitude of the longwave trough/ridge pattern. A range of AGCM sensitivity experiments explores the effect on SH blocking of tropical heating, midlatitude sea surface temperatures, and land-sea temperature gradients created over the Australian continent during austral winter. The combined effects of tropical heating and extratropical temperature gradients are further explored in a configuration that is favorable for blocking in the Australia-New Zealand sector with warm SST anomalies to the north of Australia, cold to the southwest of Australia, warm to the southeast, and cool Australian land temperatures. The blockingfavorable configuration indicates a significant strengthening of the subtropical jet and a reduction in midlatitude flow, which results from changes in the thermal wind. While these overall changes in mean climate, predominantly forced by the tropical heating, enhance blocking activity, the magnitude of atmospheric blocking compared to observations is still underestimated. The blocking-unfavorable configuration with surface forcing anomalies of opposite sign results in a weakening subtropical jet, enhanced midlatitude flow, and significantly reduced blocking.
\end{abstract}

\section{Introduction}

In the midlatitudes, atmospheric blocking represents an important feature for regional climate and weather patterns. During a blocking situation, the large-scale zonal flow is impeded and meridional anomalies occur at upper levels; the anomalous circulation pattern remains largely stationary and generally persists for several days at a time. Blocking not only influences midlatitude mean

\footnotetext{
* Current affiliation: Department of Physical Oceanography, Woods Hole Oceanographic Institution, Woods Hole, Massachusetts.

Corresponding author address: Caroline C. Ummenhofer, Department of Physical Oceanography, Woods Hole Oceanographic Institution, 266 Woods Hole Rd., MS 21, Woods Hole, MA 02543. E-mail: cummenhofer@whoi.edu
}

climate but also plays an important role in extreme events, such as heat waves and droughts (e.g., Sillmann and Croci-Maspoli 2009; Coumou and Rahmstorf 2012, and references therein). However, despite its importance, our understanding of the factors that affect intensity and frequency of atmospheric blocking, as well as the exact physical mechanism behind these modulations, is still limited. This is especially the case for the Southern Hemisphere (SH), with its sparser coverage of extended, highquality records in the extratropics. Furthermore, owing to marked biases in the representation of atmospheric blocking in general circulation models (e.g., McIntosh et al. 2008; Scaife et al. 2010, 2011), only a few modeling studies exist that address specific factors for their potential in modulating blocking in the SH (e.g., Walsh 1994). Here, we use a series of atmospheric general circulation model (AGCM) experiments with changed surface forcing to 1) diagnose model deficiency in the 
representation of atmospheric blocking in a more mechanistic way and 2) systematically evaluate the sensitivity of $\mathrm{SH}$ atmospheric blocking to a range of factors proposed in previous work. This dual purpose is at the heart of the present study with the aim of an improved understanding both factors modulating $\mathrm{SH}$ atmospheric blocking and biases in its representation in climate models.

Significant precipitation events in the $\mathrm{SH}$ midlatitudes during the cool season are often associated with cutoff low pressure systems, as demonstrated for southern Australia (Pook et al. 2006; Risbey et al. 2009; Grose et al. 2012), southern South America (e.g., Campatella and Possia 2007), and southern Africa (Singleton and Reason 2007). Such closed lows in the midtroposphere, detached from the westerly flow of the jet stream, occur more frequently around the three midlatitude $\mathrm{SH}$ continental landmasses during the cool season (Fuenzalida et al. 2005; Reboita et al. 2010, and references therein). Using synoptic decomposition for southeastern Australian rainfall events, Pook et al. (2006) found $50 \%$ of the total cool-season (April-October) rainfall and $80 \%$ of high-rainfall events to be associated with cutoff low systems. Much of the decline in rainfall in southeastern Australia over recent decades can be attributed to a decline in cutoff low rainfall (Pook et al. 2009; Risbey et al. 2013).

Atmospheric blocking in the SH extratropics is a key ingredient in the formation of cutoff lows, and both of these peak in the Australia-New Zealand sector (Taljaard 1972). They are associated with a split of the westerly flow in the upper troposphere into two separate branches (Risbey et al. 2009), which favors the detachment of closed low pressure systems from the main westerly flow and equatorward "steering" in these branches. This accounts for the initially counterintuitive finding of Pook et al. (2006), who report significant positive correlations between days with cutoff rainfall in southeastern Australia and atmospheric blocking in the Australian sector. This role of wintertime atmospheric blocking in southeastern Australia is thus distinct from the more well-known association with summer heat waves in Australia (Hudson et al. 2011; Pezza et al. 2012) and Europe (e.g., Sillmann and Croci-Maspoli 2009; Coumou and Rahmstorf 2012, and references therein). Substantial decreases in cutoff low pressure rainfall over southern regions of Australia have been projected for the twenty-first century, using a regional model, linked to changes in the blocking in the Tasman Sea region and the split structure in the jet over the region (Grose et al. 2012). In light of these projected changes, a better understanding of the representation of $\mathrm{SH}$ atmospheric blocking, a decisive factor for the formation of cutoff low rainfall, in GCMs is warranted.
During austral winter, the zonal flow in the AustraliaNew Zealand sector is characterized by a distinct splitjet flow structure at upper levels, with an area of weak westerlies in between at midlatitudes (Bals-Elsholz et al. 2001). Taljaard (1972) highlighted the importance of the wintertime split jet in the Australia-New Zealand sector for the SH region's characteristics of blocking, cutoff lows, storm tracks, and upper-air circulation. He proposed that the split jet, its existence, specific position, and strength were determined by the wintertime cooling of the Australian continent relative to the warm sea surface temperatures (SST) to the south: this results in locally enhanced baroclinicity over southern regions of Australia, as well as an equatorward shift of the meridional temperature gradient over the region. The split-jet feature and incidence of atmospheric blocking are intricately linked (e.g., Trenberth and Mo 1985), as indicated by the colocation of the split-flow feature and maximum of blocking activity in the longitude range $160^{\circ} \mathrm{E}-160^{\circ} \mathrm{W}$ in the SH midlatitudes (van Loon 1956).

While the subtropical jet exists as a quasi-steady feature on interannual time scales, Bals-Elsholz et al. (2001) found that it was the variations in the polar front jet that determined the magnitude in the split flow over the Australia-New Zealand region. As such, large-scale baroclinic processes affecting the polar front jet contribute to modulations in the split jet and associated blocking situations. Renwick and Revell (1999) attributed variations in blocking activity to both highfrequency baroclinic wave activity in the region, as well as the low-frequency mean flow field giving rise to blocking anticyclones and storm track characteristics. Wintertime Rossby wave breaking on the SH dynamical tropopause between the subtropical and polar front jet in the New Zealand region were associated with intermittent periods of enhanced blocking and intensified westerly flow (Berrisford et al. 2007). Peak blocking activity in the Australia-New Zealand region was also linked to a local maximum in positive synoptic eddy feedback on the low-frequency flow in the region (Kug and Jin 2009). From previous work (e.g., Wright 1974; Shutts 1986; Lau 1988), it thus becomes clear that blocking characteristics are determined both by the structure of the mean flow as well as the interaction with disturbances on the mean structure acting across a range of time scales. Here, we therefore assess the mean zonal flow characteristics and their relation to blocking in an AGCM, complemented by a series of sensitivity experiments that explore the role of surface forcing in providing anomalous disturbances to the mean flow field.

State-of-the-art climate models still considerably underestimate atmospheric blocking. Assessing Northern Hemisphere (NH) blocking characteristics across a 
range of models from phase 3 of the Coupled Model Intercomparison Project (CMIP3), Vial and Osborn (2012) found the frequency of blocking episodes to be underestimated owing to an excessive number of shortlived blocking events at the expense of prolonged blocking episodes. Such deficiencies have often been attributed to insufficient horizontal resolution, where small-scale features, such as atmospheric eddies important for maintaining larger-scale blocking patterns through positive feedbacks, are insufficiently resolved (Kug and Jin 2009; Scaife et al. 2011, and references therein). While higher horizontal resolution does improve biases in blocking (e.g., Tibaldi et al. 1997; Ringer et al. 2006; Matsueda et al. 2010), underestimates of blocking activity were linked to errors in the mean model climatology (Scaife et al. 2010, 2011). This echoes early work by Kaas and Branstator (1993), who found the zonal mean state in numerical simulations to be highly influential for blocking activity. When correcting the model bias in the climatological mean fields used for calculating the blocking statistics by replacing it with the observed climatological fields, Scaife et al. (2010) found NH blocking frequency and spatial patterns to be vastly improved across a series of CMIP3 models. They concluded that it was therefore errors in the model mean state, rather than its variability, that were linked to the underestimate of model blocking, exacerbated by the fact that absolute measures were commonly used to calculate blocking statistics (Scaife et al. 2010). Thus, it seems to be the more realistic representation of the mean state at higher resolution that improves the blocking activity in models, not necessarily the better upscale maintenance of blocking structures through resolved small-scale eddies. For example, in the Hadley Centre Global Environment Model, version 3 (HadGEM3) at N96 resolution, Scaife et al. (2011) found wintertime blocking in the Atlantic sector to be improved once biases in the representation of the North Atlantic Current path had been corrected with improved horizontal resolution in the ocean. The North Atlantic blocking frequency after this bias correction of the N96 simulation was comparable to a high-resolution HadGEM3 run at $\mathrm{N} 216$ resolution that did not have the erroneous North Atlantic SST features (Scaife et al. 2011). Similarly, Neale et al. (2013) attribute improvements in the representation of North Atlantic blocking in the latest version of the Community Climate System Model, version 4 (CCSM4), to a better representation of North Atlantic SST owing to a more realistic separation of the Gulf Stream.

This raises the importance of extratropical SST for atmospheric blocking. In early work on SH blocking, observed warming in the Tasman Sea seemed to be associated with more frequent blocking anticyclones in the South Tasman Sea (Simpson and Downey 1975). Using numerical simulations, they investigated the atmospheric response to warm SST anomalies in the SH midlatitudes and found distinct differences in baroclinicity and cyclonicity, likely mediated through changes in latent heat release, though not directly collocated with the SST anomalies. This is consistent with the enhanced wintertime land-sea temperature gradient created by warm SST to the south in conjunction with relatively cool land temperatures over Australia, which was proposed to be responsible for the peak in blocking activity in the region (Taljaard 1972). In a case study of SH wintertime blocking in 1982, Noar (1983) described covariability between extratropical SST anomalies and the location of enhanced blocking, suggesting that thermal forcing could be instrumental for maintenance of the block for sustained periods of time owing to a positive ocean-atmosphere feedback. The observed SST to the south of Australia showed a distinct cool (warm) anomaly pattern to the southwest (southeast) of Australia (Noar 1983), consistent with the blockingfavorable temperature gradient by Taljaard (1972). Extratropical storm tracks have been found as a region of blocking event genesis, with a preferred downstream location of blocking at the eastern edge of major NH storm tracks (Lupo and Smith 1995; Croci-Maspoli et al. 2007). Given this link, the effect of extratropical SST on storm tracks could also impact blocking. Investigating the sensitivity of the NH extratropical storm tracks to SST in a regional atmospheric model, Woollings et al. (2010) highlighted the importance of sufficient horizontal resolution for resolving gradients in SST, such as those associated with the Gulf Stream, to realistically represent the position of storm tracks. Similarly, in idealized AGCM experiments, several studies raised the importance of the latitudinal position of meridional SST (gradients) for midlatitude storm tracks (Graff and LaCasce 2012; Ogawa et al. 2012).

In contrast to the influence of regional/local SST (gradients) in the extratropics for atmospheric blocking, the importance of tropical SST for midlatitude blocking has been highlighted (e.g., Ferranti et al. 1994; Hinton et al. 2009). Ferranti et al. (1994) described enhanced Pacific wintertime blocking in European Centre for Medium-Range Weather Forecasting (ECMWF) simulations with warm SST anomalies over the Maritime Continent to correct dry model biases there. Using idealized AGCM experiments with anomalous SST over the Maritime Continent and the tropical Pacific, Hinton et al. (2009) found that the reduced frequency in wintertime North Pacific blocking could be linked to a systematic underestimation of convective activity over the 
Maritime Continent. For the SH, Renwick (1998) linked variations in the blocking activity in the South Pacific to tropical SST anomalies associated with ENSO, giving rise to anomalous convection and divergence in the tropics and transmitted to the extratropics through Rossby wave propagation (Renwick and Revell 1999). This way, variations in atmospheric blocking might be the conduit for remote transmission of tropical influences in the Indo-Pacific region, mediated by Rossby waves, on midlatitude precipitation in Australia (Cai et al. 2011; Timbal and Hendon 2011).

Thus, a series of factors have been hypothesized to influence variability in atmospheric blocking related in varying degrees to the broad "warm-ocean/cold-land anomaly pattern...linked to a dynamical environment favorable for blocking" (Haekkinen et al. 2011). Here, we aim to systematically explore the relative role of the contributing factors to this overall hypothesis using blocking in the Australia-New Zealand sector as an example: the "warm-ocean/cold-land anomaly pattern" can be generated through changes in 1) tropical SST north of Australia, 2) extratropical SST to the south, 3) anomalous land temperatures across the Australian continent, or 4) a combination thereof. Using AGCM simulations, this study quantifies the relative contributions to atmospheric blocking of these factors, as well as the mechanism by which changed temperature gradients modulate blocking characteristics.

This paper is structured as follows. Section 2 describes the reanalysis products, AGCM experiments, and blocking indices used. The model mean climatology, as it pertains to $\mathrm{SH}$ atmospheric blocking, is described in section 3. The effect on blocking of SST for 1989 (a year with high blocking) is presented in section 4 . Sections 5 and 6 explore the role of the extratropical temperature gradients and tropical heating for $\mathrm{SH}$ blocking, respectively. The combined effects of surface forcing for $\mathrm{SH}$ blocking are discussed in section 7. Section 8 then summarizes our main conclusions.

\section{Datasets and model experiments}

\section{a. Reanalysis products}

A series of gridded monthly reanalysis products were used in this study. SST data were based on the Hadley Centre Sea Ice and Sea Surface Temperature (HadISST) product by the Met Office at $1^{\circ}$ spatial resolution for the period 1956-2011 (Rayner et al. 2003). We also use the reanalysis product by the National Centers for Environmental Prediction (NCEP) and National Center for Atmospheric Research (NCAR) at a spatial resolution of $\sim 2.5^{\circ}$ latitude/longitude (Kalnay et al. 1996; Kistler et al. 2001). Atmospheric fields from

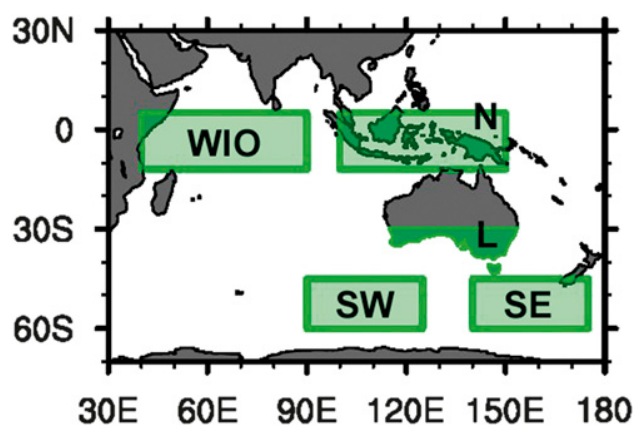

FIG. 1. Schematic indicating regions where anomalous surface forcing was employed in the corresponding experiments in Table 1.

the NCEP-NCAR reanalysis (NNR) are assessed for the period 1956-2011 as well as the shorter, higherquality record post-1979 after the advent of satellites. To test the robustness of our findings, key analyses were also repeated with data from the 40-yr ECMWF ReAnalysis (ERA-40) data for the period 1957-2002 (Uppala et al. 2005). Given qualitatively similar results, we only show those for the longest available record based on NNR for the period 1956-2011.

\section{b. AGCM experiments}

The model simulations in this study are based on the NCAR Community Atmosphere Model, version 3 (CAM3), which is the atmospheric component of the Community Climate System Model, version 3 (CCSM3). CAM3 uses a spectral dynamical core, 26 vertical levels, and was run at $\mathrm{T} 85$ horizontal resolution (approximately $1.8^{\circ}$ latitude/longitude). A detailed description of CAM3 can be found in Collins et al. (2006a) and Hurrell et al. (2006). Other model-specific aspects relevant to this study are described in Hack et al. (2006b) in relation to the model's simulation of the hydrological cycle, tropical Pacific variability (Zelle et al. 2005; Deser et al. 2006), and specifically the climate of the Australian region (Ummenhofer et al. 2008, 2009).

A 120-yr control simulation was forced with a monthly global climatological SST dataset (Hurrell et al. 2008), which combines data based on Reynolds SST (Smith and Reynolds 2003, 2004) and HadISST anomalies (Rayner et al. 2003) at $1^{\circ}$ horizontal resolution. This simulation is denoted CTRL. Additionally, a 60-yr simulation was forced with interannually varying SST for the period 1951-2010 based on Smith and Reynolds (2003, 2004), denoted $\mathrm{SST}_{\text {real. }}$. A series of idealized perturbation experiments of 100-yr duration were conducted in which local SST anomalies over a specific domain were superimposed on the Hurrell et al. (2008) global SST climatology. Figure 1 highlights the areas where SST anomalies of $\pm 1.5^{\circ} \mathrm{C}$ magnitude were added. To avoid 
TABLE 1. Summary of AGCM simulations described in the study: acronym used in the text is indicated, as well as the location (and magnitude) of the anomalies superimposed on climatological forcing (CLIM) for the respective regions shown in Fig. 1. Warm/cold anomalies refer to changes in SST, while warm*/cold* indicate a change in the surface land temperature.

\begin{tabular}{|c|c|c|c|c|c|c|}
\hline \multirow[b]{2}{*}{ Acronym } & \multirow[b]{2}{*}{ CLIM } & \multicolumn{5}{|c|}{ Location (magnitude) of anomaly } \\
\hline & & $\mathrm{N}\left( \pm 1.5^{\circ} \mathrm{C}\right)$ & $\mathrm{L}\left( \pm 5^{\circ} \mathrm{C}\right)$ & $\mathrm{SW}\left( \pm 1.5^{\circ} \mathrm{C}\right)$ & $\mathrm{SE}\left( \pm 1.5^{\circ} \mathrm{C}\right)$ & WIO $\left( \pm 1.5^{\circ} \mathrm{C}\right)$ \\
\hline CTRL & $\boldsymbol{\nu}$ & - & - & - & - & - \\
\hline $\mathrm{SST}_{\text {real }}$ & - & - & - & - & - & - \\
\hline$N_{w}$ & $\boldsymbol{\nu}$ & warm & - & - & - & - \\
\hline$N_{c}$ & $\boldsymbol{\nu}$ & cold & - & - & - & - \\
\hline $\mathrm{WIO}_{w}$ & $\boldsymbol{\nu}$ & - & - & - & - & warm \\
\hline $\mathrm{WIO}_{c}$ & $\boldsymbol{\nu}$ & - & - & - & - & cold \\
\hline$L_{w}$ & $\boldsymbol{\nu}$ & - & warm* & - & - & - \\
\hline$L_{c}$ & $\boldsymbol{\nu}$ & - & cold* & - & - & - \\
\hline $\mathrm{SW}_{c}$ & $\boldsymbol{\nu}$ & - & - & cold & - & - \\
\hline $\mathrm{SE}_{w}$ & $\boldsymbol{\nu}$ & - & - & - & warm & - \\
\hline $\mathrm{SW}_{c}+\mathrm{SE}_{w}$ & $\boldsymbol{\nu}$ & - & - & cold & warm & - \\
\hline$L_{c}+\mathrm{SW}_{c}+\mathrm{SE}_{w}$ & $\boldsymbol{\nu}$ & - & cold* & cold & warm & - \\
\hline$L_{w}+\mathrm{SW}_{w}+\mathrm{SE}_{c}$ & $\boldsymbol{\nu}$ & - & warm* & warm & cold & - \\
\hline $\mathrm{BL}_{\max }$ & $\boldsymbol{V}$ & warm & cold* & cold & warm & - \\
\hline $\mathrm{BL}_{\min }$ & $\nu$ & cold & warm* & warm & cold & - \\
\hline
\end{tabular}

spurious responses in the atmospheric model related to unrealistic gradients at the edge of the anomalies, smoothing has been applied, with a tapering of SST anomalies over a $10^{\circ}$ latitude/longitude range centered on the edge of the domains highlighted in Fig. 1. The same SST anomaly pattern was superimposed on the climatological SST throughout the year.

Table 1 provides a summary of the different experiments and the acronyms used throughout the remainder of the study. The experiments explore the relative role of several factors that have been implicated in affecting atmospheric blocking in the Australia-New Zealand sector. These include the role of regional SST and landsea temperature gradients. Below, a list is provided of the factors the various experiments assess and the regional extent of the anomalies used:

- tropical SST around the Maritime Continent within $5^{\circ} \mathrm{N}-12^{\circ} \mathrm{S}, 100^{\circ}-150^{\circ} \mathrm{E}$ - denoted $N_{w}$ and $N_{c}$ for the warm and cold case, respectively;

- western Indian Ocean SST within $5^{\circ} \mathrm{N}-12^{\circ} \mathrm{S}, 40^{\circ}-$ $90^{\circ} \mathrm{E}$ - denoted $\mathrm{WIO}_{w}$ and $\mathrm{WIO}_{c}$ for the warm and cold case, respectively;

- SST to the south of Australia with cold anomalies within $45^{\circ}-60^{\circ} \mathrm{S}, 90^{\circ}-125^{\circ} \mathrm{E}$ and warm anomalies $45^{\circ}-$ $60^{\circ} \mathrm{S}, 140^{\circ}-175^{\circ} \mathrm{E}$-denoted $\mathrm{SW}_{c}$ and $\mathrm{SE}_{w}$, respectively;

- zonal temperature gradient south of Australia with both cold anomalies within $45^{\circ}-60^{\circ} \mathrm{S}, 90^{\circ}-125^{\circ} \mathrm{E}$ and warm anomalies $45^{\circ}-60^{\circ} \mathrm{S}, 140^{\circ}-175^{\circ} \mathrm{E}$-denoted $\mathrm{SW}_{c}+\mathrm{SE}_{w}$;

- surface land temperature over southern regions of Australia with warm and cold anomalies over the land area enclosed by $30^{\circ}-45^{\circ} \mathrm{S}, 113^{\circ}-155^{\circ} \mathrm{E}$-denoted $L_{w}$ and $L_{c}$;

- changed land-sea temperature configuration by combining the Australian surface land temperature anomalies and zonal SST gradient to the south of Australia in order to produce a most and least favorable state for blocking according to hypotheses stated earlier-denoted $L_{c}+\mathrm{SW}_{c}+\mathrm{SE}_{w}$ and $L_{w}+\mathrm{SW}_{w}+\mathrm{SE}_{c}$, respectively;

- a configuration that is maximizing and one that is minimizing atmospheric blocking by using the SST anomalies to the north and south of Australia and the Australian land temperature in the most/least favorable configuration for blocking - denoted $\mathrm{BL}_{\max }$ and $\mathrm{BL}_{\min }$, respectively.

Other factors that were investigated included horizontal model resolution of CAM3 and changes in the model's surface topography. As we only briefly refer to these results, but do not present them in this study, no indepth description of the model experiments is provided.

\section{c. Blocking index}

The blocking index (BI) predominantly used in this study is based on Pook and Gibson (1999) and is calculated as follows:

$$
\mathrm{BI}=0.5\left(U_{25}+U_{30}-U_{40}-2 U_{45}-U_{50}+U_{55}+U_{60}\right),
$$

where $U_{x}$ indicates the zonal wind at the $500-\mathrm{hPa}$ level for latitude $x$ : larger values in the $\mathrm{BI}$ indicate favorable blocking conditions. The BI is well suited to assess blocking in the Australia-New Zealand sector and has previously been used to successfully evaluate the effect of blocking on Australian rainfall (e.g., Risbey et al. 2009). We calculate the BI across all longitudes and then 

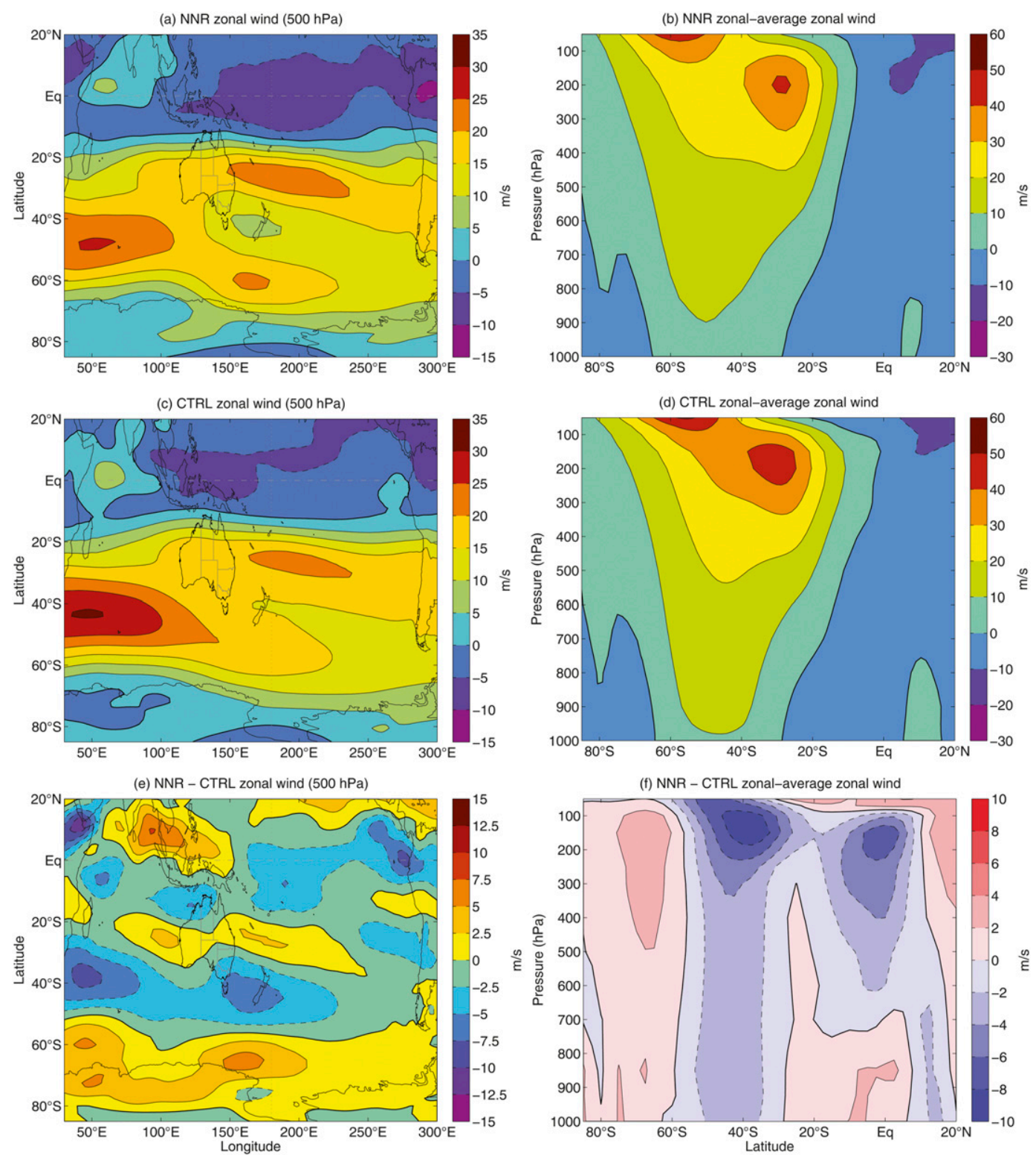

FIG. 2. Long-term mean zonal wind in reanalysis and model simulations during JJA at the 500-hPa level based on the (a) NNR and (c) 120-yr CTRL and (e) their difference; zonal-average zonal wind based on the (b) NNR and (d) CTRL simulation and (f) their difference.

focus on $160^{\circ} \mathrm{E}$ as a longitude typical of blocking for the Australia-New Zealand sector (Taljaard 1972). There the BI can be seen to consist of three separate components that make up the total BI given in Eq. (1): 1) the northern component measured by the zonal flow at $25^{\circ}-$ $30^{\circ} \mathrm{S}$, indicative of the strength of the subtropical jet; 2) the middle component as the "slow down" of zonal flow in midlatitudes at $40^{\circ}-50^{\circ} \mathrm{S}$; and 3) the southern component assessing the zonal flow at $55^{\circ}-60^{\circ} \mathrm{S}$, reflecting the strength of the polar front jet. This can be seen in Fig. 2a when focusing on the relevant longitude. As such, the $\mathrm{BI}$ is a split-flow index, which gives the highest values at a meridian when the low and high latitude components are at a maximum and the midlatitude component is at a minimum. Hence, a dipolar block is readily identified by the BI. An "isolated" high (i.e., one without a strong cyclonic component at lower latitudes) will normally be identified by the BI since the midlatitude westerlies will be reduced and the highlatitude westerlies enhanced in this configuration. For further details, the reader is referred to Pook et al. (2013). 
The BI in Eq. (1) is appropriate for use in the Australian region given its specific design for the region and inclusion of a northern component measuring the strength of the subtropical jet, which is missing in other definitions of the BI (e.g., Tibaldi and Molteni 1990; Tibaldi et al. 1994). Hence, the BI used here is a more comprehensive measure of blocked flow for the AustraliaNew Zealand sector. A detailed comparison of the two indices reveals that results do not differ widely between the indices (Pook et al. 2013).

\section{Model mean state}

The model mean state of the $\mathrm{SH}$ atmospheric circulation is assessed, in particular as it pertains to the representation of atmospheric blocking. For further details on more general aspects of SH climate in CAM3, we refer the reader to Collins et al. (2006a,b), Hack et al. (2006b), and Hurrell et al. (2006).

\section{a. Zonal wind}

As blocking manifests as variations in the zonal flow field, long-term mean zonal winds over the Indo-Pacific sector in the model are compared with reanalysis data (Fig. 2). Given the study's focus on the austral cool season, Fig. 2 shows the zonal flow field at $500 \mathrm{hPa}$ and zonally averaged zonal winds during June-August (JJA) for NNR and the CTRL simulation, as well as their difference. Strong zonal flow in excess of $20 \mathrm{~m} \mathrm{~s}^{-1}$ at $500 \mathrm{hPa}$ is apparent over the southern Indian Ocean between $40^{\circ}$ and $60^{\circ} \mathrm{S}$ during JJA in the reanalysis (Fig. 2a). A split in the flow occurs downstream of the Australian continent east of $150^{\circ} \mathrm{E}$, with the subtropical jet centered at $25^{\circ} \mathrm{S}$ and the polar front jet at $60^{\circ} \mathrm{S}$. An area of decreased westerly flow lies over the Tasman Sea and New Zealand region centered at $40^{\circ} \mathrm{S}$ during austral winter. It is this area of reduced westerly flow that can favor a blocking situation. Overall, the wintertime split zonal flow structure in Fig. 2a is in agreement with Bals-Elsholz et al. (2001). In the CTRL simulation, the magnitude of the zonal winds with flow in excess of $30 \mathrm{~m} \mathrm{~s}^{-1}$ are overestimated in the southern Indian Ocean (Figs. 2c,e). While the magnitude of the subtropical jet in the CTRL is comparable to NNR at $500 \mathrm{hPa}$, its maximum location is displaced eastward (Fig. 2c). The polar jet in the model is less well defined and pronounced than in NNR, with the region of reduced zonal flow around New Zealand almost nonexistent in the model. The overly strong extratropical $\mathrm{SH}$ zonal wind field in the model is related to systematic errors in the pressure field and transient momentum flux, an Antarctic circumpolar trough that is too deep throughout the year (Hurrell et al. 2006), as well as excessive surface wind stress in the storm tracks (Collins et al. 2006b).

The zonally averaged wind confirms the overestimation of the magnitude of zonal winds in $\mathrm{SH}$ midlatitudes throughout the atmospheric column in the CTRL compared to NNR (Figs. 2b,d,f). The bias is particularly pronounced for the polar and subtropical jet at height, while at the surface the zonal flow is overestimated by up to $5 \mathrm{~m} \mathrm{~s}^{-1}$ in the zonal average at $35^{\circ}-55^{\circ} \mathrm{S}$ in the CTRL. Overall, the zonal winds in the CTRL do not represent the split flow over the Australia-New Zealand sector seen in the NNR climatology during wintertime (Fig. 2), with large implications for the representation of blocking in the region.

\section{b. Blocking}

To assess the model's representation of SH blocking, the BI described in section 2c is used, based on Pook and Gibson (1999). It is of interest to compare observed and model blocking, both in terms of location and seasonality of blocking activity across the SH. The mean seasonal cycle of total BI is thus shown across all longitudes in Figs. 3a-c for NNR, CTRL, and their difference, respectively. It highlights the enhanced blocking activity in the Australia-New Zealand sector $140^{\circ} \mathrm{E}-160^{\circ} \mathrm{W}$ for NNR, as well as the predominant activity during the austral cool season (Fig. 3a). The model broadly captures the maximum blocking location centered at $180^{\circ}$ and predominant season of enhanced wintertime blocking (Fig. 3b). However, the magnitude of the blocking is severely underestimated throughout the year, but in particular during late winter and early spring (AugustOctober) around $180^{\circ}$ (Figs. 3b,c). Blocking activity also extends too far east in the CTRL, compared to the narrower band centered at $180^{\circ}$ in NNR.

As detailed previously, the BI can be separated into its constituent components, northern, middle, and southern BI component. The northern component, indicative of the strength of the subtropical jet, is overall well captured by the model (Figs. 3d-f). Maximum values in the northern BI component are observed during JuneSeptember and centered at $180^{\circ}$ (Fig. 3d); while the maximum values in the CTRL do not extend into September and reach slightly too far east beyond $140^{\circ} \mathrm{W}$ (Fig. 3e), the broad pattern and, in particular, magnitude of the BI component at subtropical latitudes is well represented (Fig. 3f). Similarly, the mean location, seasonality, and magnitude of the southern component of the BI, with its two maxima during March-May and September-October at $160^{\circ} \mathrm{E}-180^{\circ}$, is well simulated in the CTRL (Figs. 3j-1). It is the reduced westerly flow at midlatitudes that is not captured well in the model: the mid-BI component has a pronounced maximum at 
NNR

(a) BI total

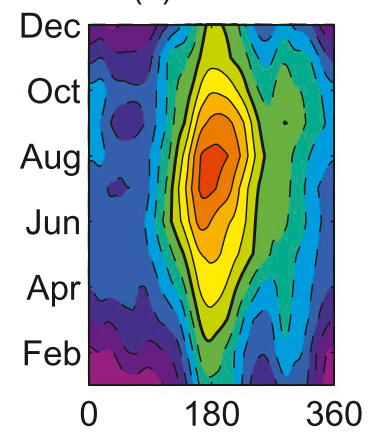

(d) BI north

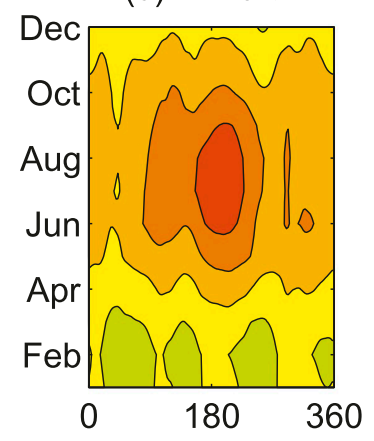

(g) BI mid

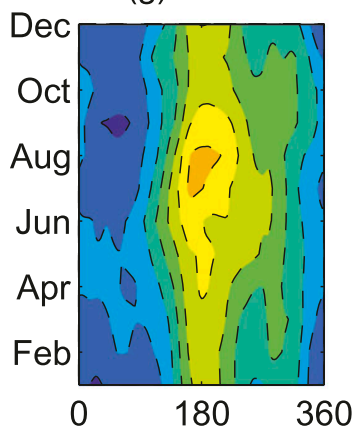

(j) BI south

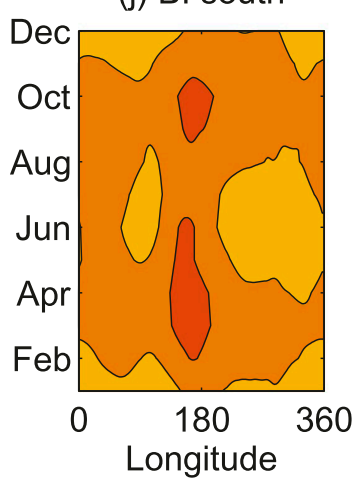

CTRL

(b) BI total

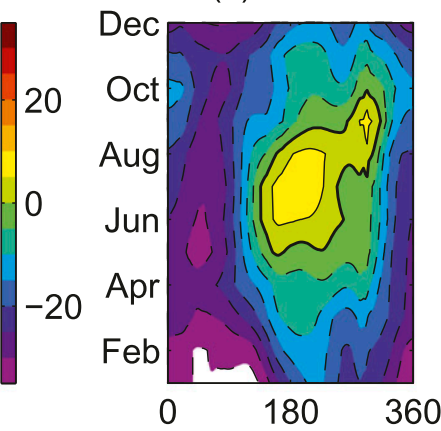

(e) BI north

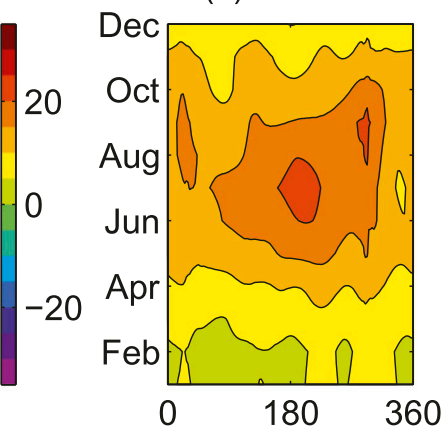

(h) BI mid

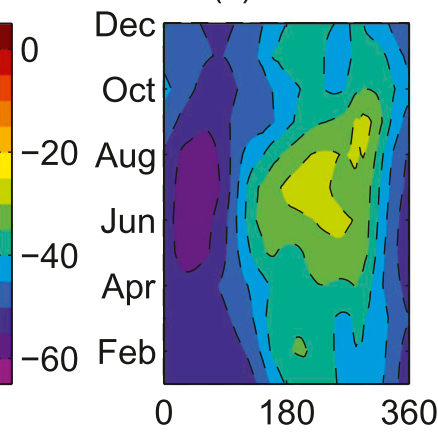

(k) BI south

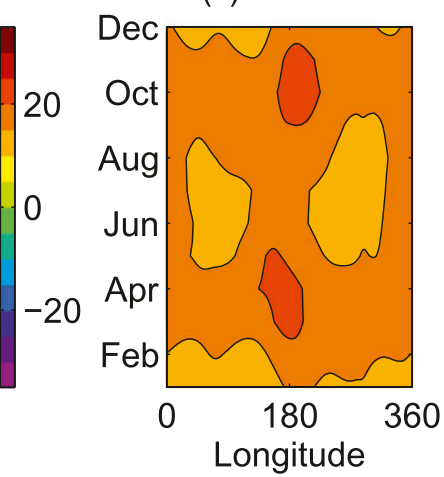

NNR - CTRL

(c) BI total

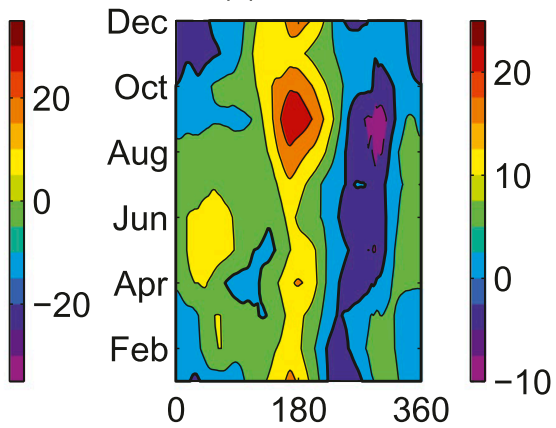

(f) BI north

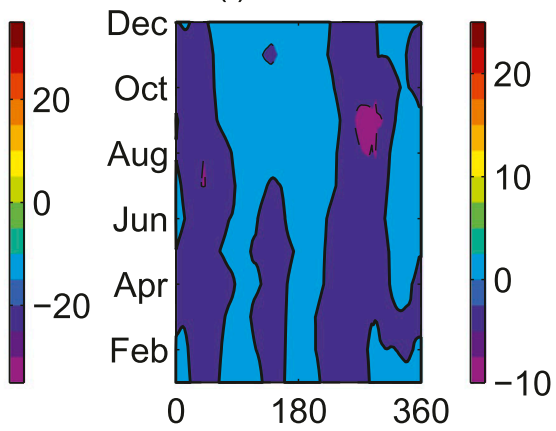

(i) $\mathrm{BI}$ mid

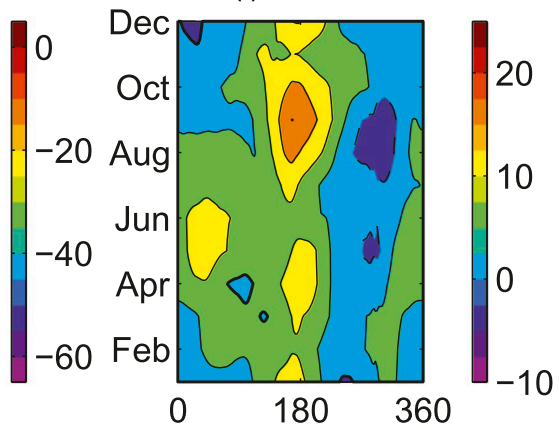

(I) BI south

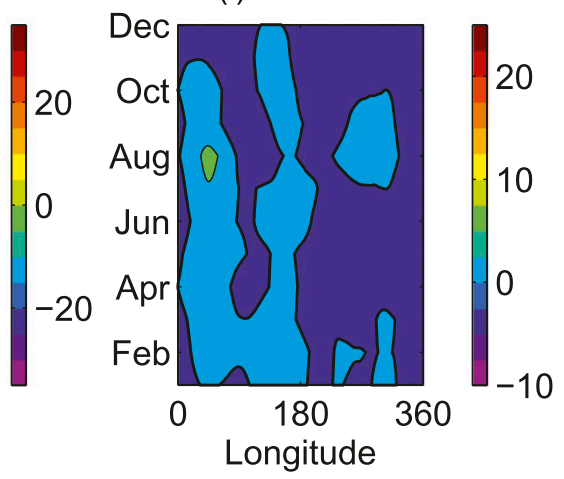

FIG. 3. Seasonal cycle of blocking index vs longitude for (left) NNR, (middle) CTRL, and (right) their difference for the (a)-(c) total BI and (d)-(f) north, (g)-(i) middle, and (j)-(l) south components. 
$160^{\circ} \mathrm{E}-160^{\circ} \mathrm{W}$ during July and August in the observed (Fig. 3g), while the values are much lower in the CTRL and displaced eastward to $180^{\circ}-120^{\circ} \mathrm{W}$ (Fig. 3h). It should be noted that the middle component shown in the histograms has been multiplied by -1 to reflect the slowing down of the flow during a blocking situation: that is, the smaller the value of the middle component, the larger the total BI [see Eq. (1)]. In fact, the slowdown in the modeled mean zonal flow at midlatitudes is underestimated throughout the year for the longitude band $120^{\circ} \mathrm{E}-160^{\circ} \mathrm{W}$, in particular in the range $160^{\circ} \mathrm{E}-180^{\circ}$ of importance for the Australian region (Fig. 3i).

To focus more specifically on the wintertime variability of the BI over time, Fig. 4 presents the fitted normal distribution of the $\mathrm{BI}$ at $160^{\circ} \mathrm{E}$ averaged over the JJA months for NNR, as well as the CTRL and $\mathrm{SST}_{\text {real }}$ simulations. The longitude $160^{\circ} \mathrm{E}$ was chosen owing to its importance for blocking in the Australia-New Zealand sector (Taljaard 1972). Comparison with the BI at longitudes $140^{\circ} \mathrm{E}-180^{\circ}$ reveals very similar results, though, indicating that $160^{\circ} \mathrm{E}$ is representative more broadly of the region's blocking characteristics. A fitted distribution of the JJA BI is used to account for the different number of years in the NNR and various model simulations. When only a subset of years of equal size is chosen for NNR and the AGCM simulations, results are indifferent to those using the entire set of years available in the simulations (figure not shown). Throughout the remainder of the study, therefore, the largest available set of years is used for each analysis.

The total BI for NNR has a mean of 17.8 , which is significantly higher than the mean BI for the CTRL (4.16) and the $\mathrm{SST}_{\text {real }}$ (5.8) simulation (Fig. 4a). While the mean BI in $\mathrm{SST}_{\text {real }}$ is slightly higher than in the CTRL, the difference is not significant at the $95 \%$ confidence level. The variability of the BI within NNR and the model is comparable with an equal spread around the mean, as attested by overlapping $95 \%$ confidence intervals for the standard deviations.

The total BI is further decomposed into its constituent components to assess which components contribute to the bias in the model BI relative to NNR (Figs. 4b-d). The northern component of the BI in the model is well represented: the mean $\mathrm{BI}$ in neither CTRL nor $\mathrm{SST}_{\text {real }}$ differs significantly from the NNR value of 19.6 (Fig. 4b). However, there are significant biases in the middle component, with a mean of 21.2 for NNR compared to the means of 33.0 and 31.2 for CTRL and $\mathrm{SST}_{\text {real }}$, respectively. Again, while the mean in $\mathrm{SST}_{\text {real }}$ is indicative of slightly enhanced blocking for the middle component compared to the CTRL, the difference is not significant at the $95 \%$ confidence level. For the southern component of the BI, the CTRL does not differ significantly from

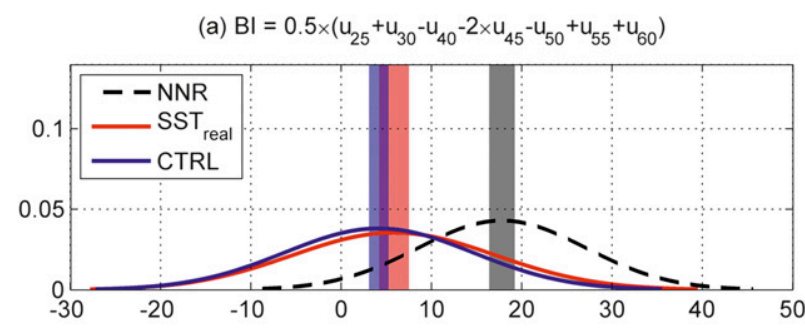

(b) BInorth $=0.5 \times\left(u_{25}+u_{30}\right)$

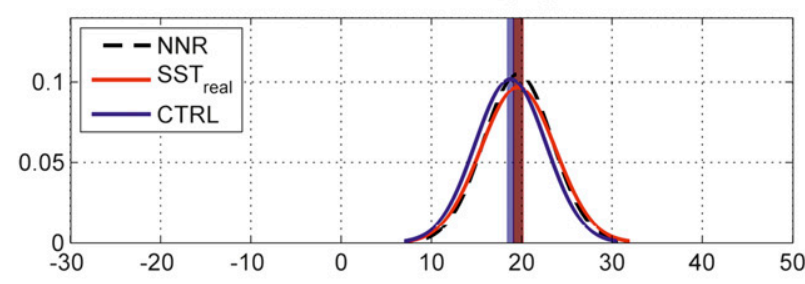

(c) - BImid $=0.5 \times\left(u_{40}+2 \times u_{45}+u_{50}\right)$

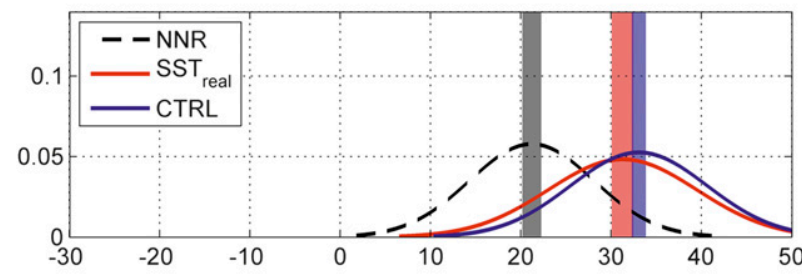

(d) Blsouth $=0.5 \times\left(u_{55}+u_{60}\right)$

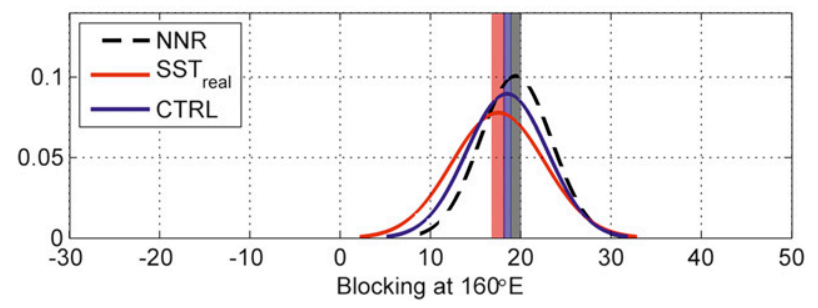

FIG. 4. Fitted distribution of JJA blocking index at $160^{\circ} \mathrm{E}$ from reanalysis and model experiments for NNR (black), CTRL (blue), and $\mathrm{SST}_{\text {real }}$ (red) for the BI components: (a) total, (b) north, (c) middle, and (d) south. Shading indicates the $95 \%$ confidence interval of the mean $\mathrm{BI}$ for the respective distributions.

the mean value of 19.4 for the NNR; however, $\mathrm{SST}_{\text {real }}$ with a mean of 17.5 shows a small, albeit significant, negative bias compared to NNR (Fig. 4c). The difference between CTRL and SST real is not significant.

It should be noted that the width of the distribution varies among the different components of the BI in Fig. 4: the distribution in the northern and southern component for both NNR and model simulations are narrower than the middle component. The considerable variability in the total BI appears to be largely due to the spread in the middle component of the BI. In other words, the degree of slowdown in the SH midlatitudes varies widely from one year to the next, both in observations and model simulations. While the model represents 
the variability in total $\mathrm{BI}$ and its components well, it consistently underestimates mean blocking, irrespective of whether climatological SST or interannually varying SST are used as boundary forcing. Similarly, Scaife et al. (2010) found that CMIP3 climate models tend to underestimate blocking in the North Atlantic sector in connection with biases in the mean state, while the year-to-year blocking variability was comparable with observations.

\section{c. Model resolution and topography}

Horizontal model resolution and model topography were other factors assessed as to their influence on atmospheric blocking in CAM3. While the wintertime BI for the Australia-New Zealand sector in CAM3 run with climatological SST at a horizontal resolution in the atmospheric model of T42 ( 2.8 latitude/longitude) was slightly lower than a comparable run at T85 $\left(\sim 1.8^{\circ}\right.$ latitude/longitude), the differences were not significant (figure not shown). Horizontal resolution in the model thus does not seem to be the primary culprit for reduced blocking frequency in atmospheric models, consistent with earlier findings (e.g., Scaife et al. 2010). This is despite the fact that the low-level dynamical circulation features in CAM3 at T85 horizontal resolution are improved relative to those at $\mathrm{T} 42$ when compared to observations (Hack et al. 2006a).

Furthermore, removing topographical features over the land areas of Australia and New Zealand in CAM3 at T85 resolution did not significantly reduce atmospheric blocking in the region compared to the CTRL (figure not shown). This is in agreement with Walsh (1994), who found considerable local effects, but no large-scale effects on the $\mathrm{SH}$ atmospheric circulation when removing the Andean topography in the Bureau of Meteorology Research Centre general circulation model. However, it is not consistent with Zidikheri et al. (2007), who found a realistic topography to be important for resolving large-scale atmospheric dynamics, including blocking. It should be noted that our results might be related to the model's deficiency in blocking, while removal of topographical features in a model with strong blocking may have a more notable impact.

\section{1989 experiment}

Given the modulating role of SST for atmospheric blocking proposed earlier, we used observed SST from a year with high blocking in the Australia-New Zealand sector as boundary forcing for the atmospheric model. A 100-yr simulation of CAM3 at T85 resolution was forced with monthly varying global observed SST during 1989. Over the more than 60 years in the observational record, the year 1989 recorded the highest mean $\mathrm{BI}$ at $160^{\circ} \mathrm{E}$ (Tasman Sea) for the June-October period and the second highest annual mean. The year was characterized by a persistent pattern of quasi-stationary anticyclones south of Australia and the Tasman Sea early in winter followed by a gradual eastward shift of blocking activity during the late winter and spring (Pook 1994). The year 1989 also featured a strong split-flow structure over the Australia-New Zealand sector, as reflected in peak values in the split-flow index by Bals-Elsholz et al. (2001).

Above-average wintertime SST anomalies surrounded the Australian continent in 1989 (Fig. 5a). Also featured were remnant anomalous cool SST in the Pacific Ocean following the La Niña of 1988 and the emergence of a negative Indian Ocean dipole event in 1989 (Meyers et al. 2007). As such, the SST anomalies in the eastern Indian Ocean were characterized by a meridional SST gradient (Fig. 5a) previously linked to anomalous wet conditions in southern regions of Australia (Ummenhofer et al. 2008, 2009): the question arises whether the precipitation increase is mediated through enhanced blocking activity and cutoff low incidence, modulated through the large-scale anomalous SST field. To the south of Australia at $50^{\circ} \mathrm{S}$, a zonal SST gradient reminiscent of Noar (1983) is apparent, with anomalous cool SST to the southwest and anomalous warm SST to the southeast (Fig. 5a).

In the 1989 experiment, the simulated BI indicates an enhancement relative to the CTRL for the AustraliaNew Zealand sector (longitudes $130^{\circ} \mathrm{E}-140^{\circ} \mathrm{W}$ ) during austral late winter and spring (July-October, Fig. 5b). A reduction in the BI to the east could indicate a westward shift in the blocking activity. The fitted distribution of JJA total BI at $160^{\circ} \mathrm{E}$ also records a shift toward higher blocking incidence (relative to the CTRL) toward the observed (Fig. 5c). This change is largely due to a better representation of the slowdown of the zonal flow at midlatitudes in the 1989 case compared to the CTRL (Fig. 5e): with a mean mid-BI value of 29.2 in 1989 compared to 33.0 for the CTRL and 21.2 in NNR. In contrast, no significant changes in the BI are seen in the 1989 experiment relative to NNR or CTRL for the southern components, reflective of the strength of the polar front jet (Fig. 5f). Furthermore, the northern BI component indicates a significantly strengthened subtropical jet with an increase in the mean BI value to 20.6 for the 1989 case relative to the CTRL (18.7, Fig. 5d).

\section{Extratropical temperature gradients}

Variations in the zonal SST gradients south of Australia have been linked to changes in blocking 

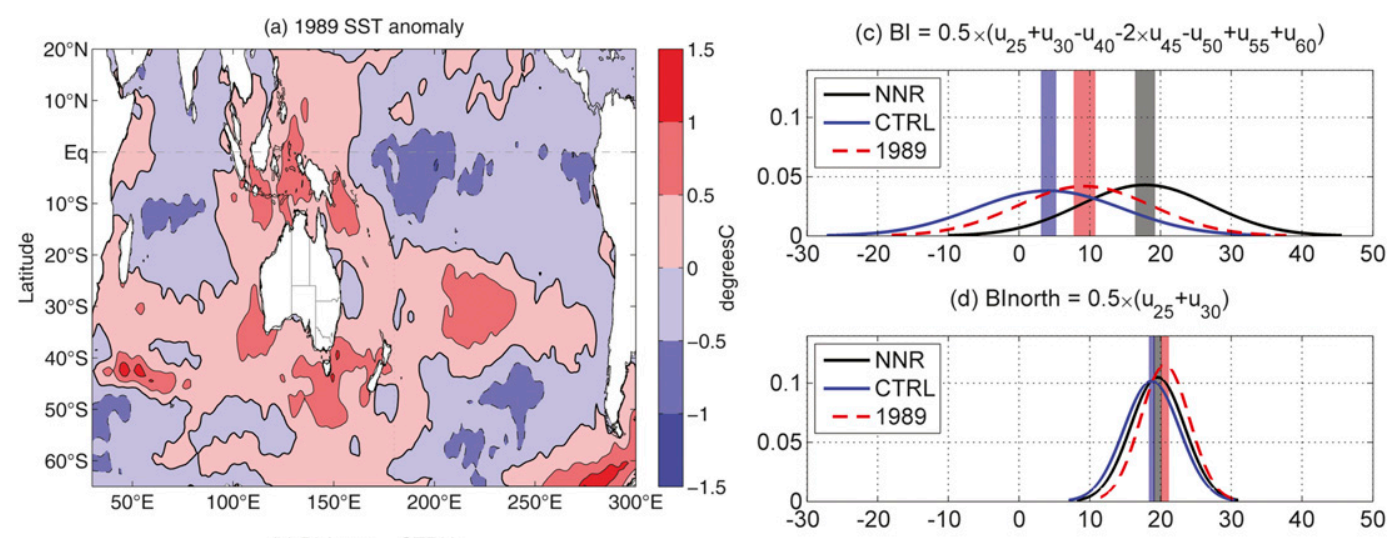

(d) BInorth $=0.5 \times\left(u_{25}+u_{30}\right)$
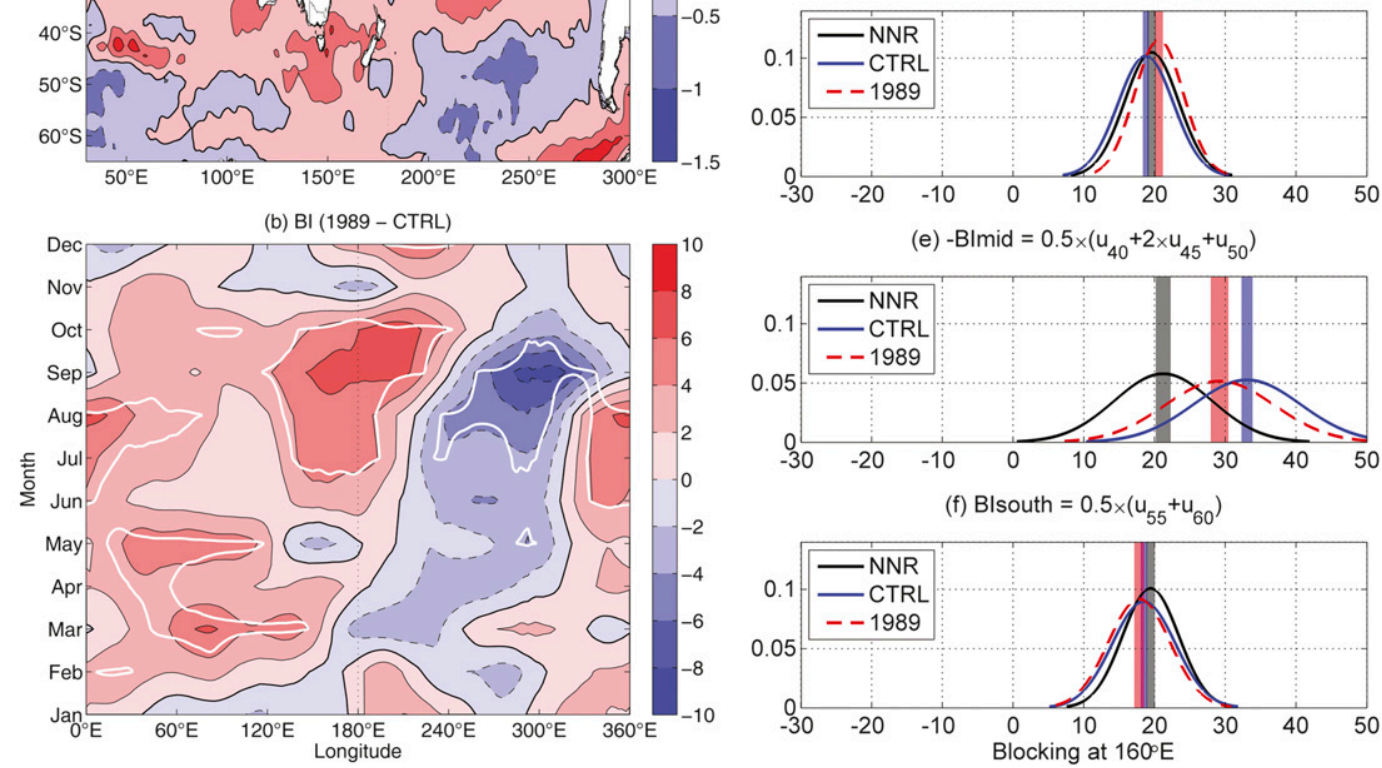

(e) - BImid $=0.5 \times\left(u_{40}+2 \times u_{45}+u_{50}\right)$
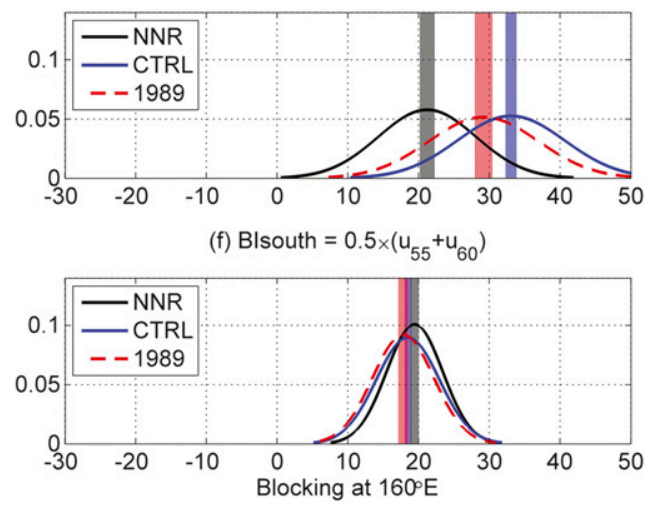

FIG. 5. (a) SST anomalies during 1989 for the JJA season and (b) seasonal cycle of blocking index vs longitude for blocking index, shown as anomaly of the 1989 experiment relative to CTRL, with significant anomalies at the $95 \%$ level delimited by the white contour. Fitted distribution of JJA blocking index at $160^{\circ} \mathrm{E}$ from reanalysis and model experiments for NNR (black), CTRL (blue), and 1989 SST (red) for the BI components: (c) total, (d) north, (e) middle, and (f) south. Shading in (c)-(f) indicates the $95 \%$ confidence interval of the mean BI for the respective distributions.

frequency/intensity in the Australia-New Zealand sector (e.g., Taljaard 1972; Bals-Elsholz et al. 2001). The effect of wintertime cooling of the Australian continent in conjunction with warmer surrounding SST has furthermore been proposed to be a decisive factor for blocking (Taljaard 1972; Pook 1994). We therefore assessed the influence of variations in the extratropical wintertime temperature gradients, both due to land temperature and SST changes, on blocking in the AustraliaNew Zealand sector through the use of idealized AGCM simulations. Regions with anomalous SST (cf. Fig. 1 and section $2 \mathrm{~b}$ ) and land temperature anomalies were used in AGCM simulations, both individually (figure not shown) and in combination.

The BI for the configuration with combined land-sea temperature gradients hypothesized to be most and least favorable for blocking is shown in Fig. 6, along with NNR and CTRL for reference. The total BI in the experiments with the extratropical temperature gradient in the $\operatorname{most}\left(L_{c}+\mathrm{SW}_{c}+\mathrm{SE}_{w}\right)$ and least $\left(L_{w}+\mathrm{SW}_{w}+\mathrm{SE}_{c}\right)$ blockingfavorable configuration do not differ significantly from the CTRL with a mean BI value of 4.2 (Fig. 6a). They therefore all considerably underestimate the NNR mean BI value of 17.8. The observed interannual variability in the BI is again well represented in the model, as attested by the overlap in standard deviations in the model with NNR. In the three model simulations, the northern BI component, reflective of the subtropical jet, does not differ significantly from NNR (Fig. 6b). The reduced zonal flow in midlatitudes with a mean value of 21.2 for the mid-BI component in NNR is not captured by any of the simulations (Fig. 6c). Again, no significant differences from the CTRL exist for either $L_{c}+\mathrm{SW}_{c}+\mathrm{SE}_{w}$ or $L_{w}+\mathrm{SW}_{w}+\mathrm{SE}_{c}$ for the mid-BI component. The agreement for the mean BI for the southern component (i.e., indicative of the strength of the polar jet) is good among NNR and the three simulations. Interestingly, the narrow distribution seen in NNR for the southern BI component is most closely represented by the $L_{w}+\mathrm{SW}_{w}+\mathrm{SE}_{c}$ experiment, while the CTRL and $L_{c}+\mathrm{SW}_{c}+\mathrm{SE}_{w}$ experiment slightly overestimate the variability in the polar front jet (Fig. 6d). 
(a) $\mathrm{BI}=0.5 \times\left(\mathrm{u}_{25}+\mathrm{u}_{30}-\mathrm{u}_{40}-2 \times \mathrm{u}_{45}-\mathrm{u}_{50}+\mathrm{u}_{55}+\mathrm{u}_{60}\right)$

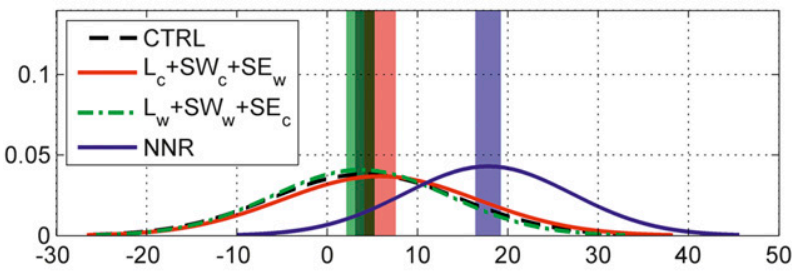

(b) BInorth $=0.5 \times\left(u_{25}+u_{30}\right)$

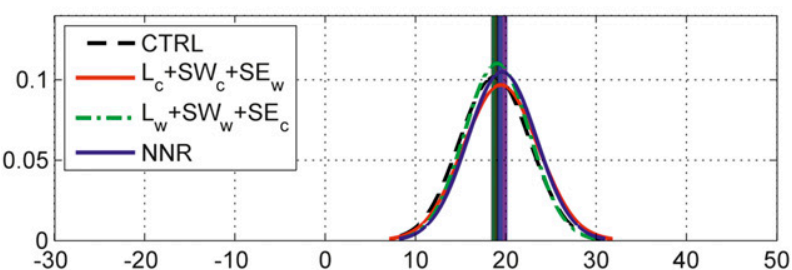

(c) - BImid $=0.5 \times\left(u_{40}+2 \times u_{45}+u_{50}\right)$

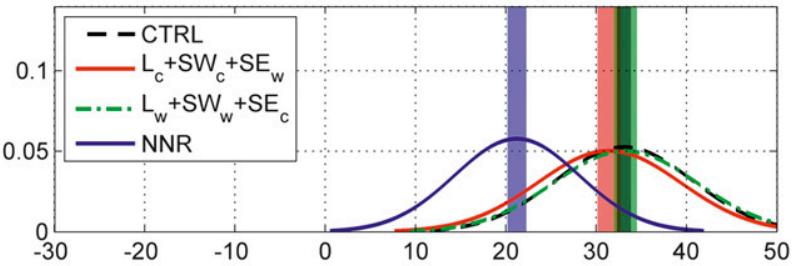

(d) Blsouth $=0.5 \times\left(u_{55}+u_{60}\right)$

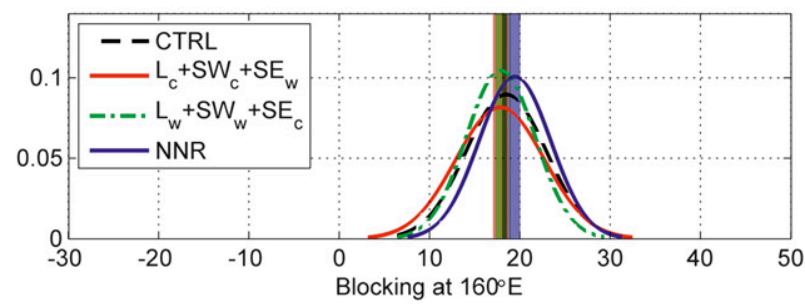

FIG. 6. Fitted distribution of JJA blocking index at $160^{\circ} \mathrm{E}$ from reanalysis and model experiments for NNR (blue), CTRL (black), and changed extratropical temperature gradients for $L_{c}+\mathrm{SW}_{c}+\mathrm{SE}_{w}$ (red), and $L_{w}+\mathrm{SW}_{w}+\mathrm{SE}_{c}$ (green) for the index components: (a) total, (b) north, (c) middle, and (d) south. Shading indicates the $95 \%$ confidence interval of the mean BI for the respective distributions.

\section{Tropical heating}

Tropical heating has been known to modulate atmospheric blocking in the extratropics, both in models (e.g., Ferranti et al. 1994; Hinton et al. 2009) and observations (e.g., Renwick and Wallace 1996). As such, underestimates of blocking in climate models have been linked to biases in tropical precipitation (Hinton et al. 2009, and references therein). Again, previous studies on the impact of tropical heating on extratropical blocking in observations and models largely focused on NH blocking. (a) $\mathrm{BI}=0.5 \times\left(\mathrm{u}_{25}+\mathrm{u}_{30}-\mathrm{u}_{40}-2 \times \mathrm{u}_{45}-\mathrm{u}_{50}+\mathrm{u}_{55}+\mathrm{u}_{60}\right)$

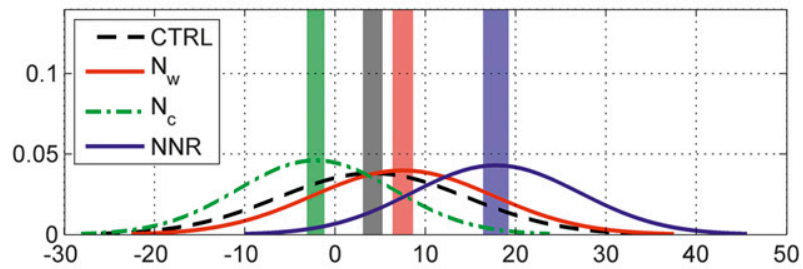

(b) BInorth $=0.5 \times\left(u_{25}+u_{30}\right)$

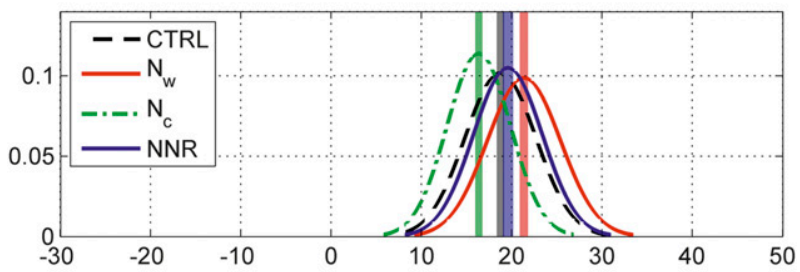

(c) - BImid $=0.5 \times\left(u_{40}+2 \times u_{45}+u_{50}\right)$

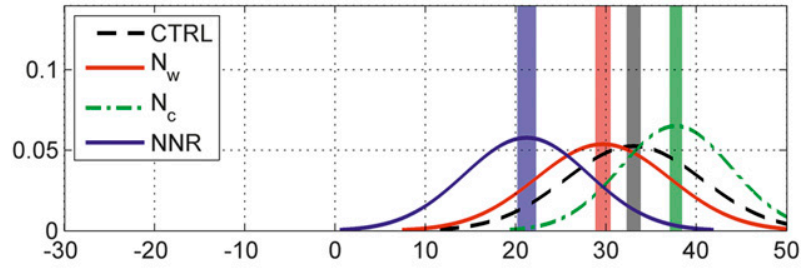

(d) Blsouth $=0.5 \times\left(u_{55}+u_{60}\right)$

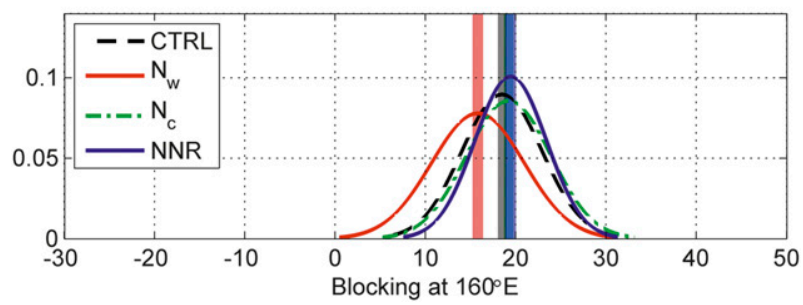

FIG. 7. As in Fig. 6, but for changed tropical heating for $N_{w}$ (red), and $N_{c}$ (green).

\section{a. North Australian SST}

Here, we explore the role of SST to the north of Australia around the Maritime Continent (Fig. 1) on blocking in the SH extratropics. The experiments with anomalous warm SST north of Australia $\left(5^{\circ} \mathrm{N}-12^{\circ} \mathrm{S}\right.$, $100^{\circ}-150^{\circ} \mathrm{E}$ ) are denoted $N_{w}$ and $N_{c}$ for the cold anomaly case, respectively. The fitted distributions of the JJA BI in the CTRL and simulations with changed tropical heating are compared to NNR in Fig. 7. The modeled total BI in all three is significantly below the mean NNR value of 17.8 (Fig. 7a). However, in the simulations with modified tropical heating, the total mean BI differs significantly from the CTRL (4.2), with a significant reduction in total BI to -2.2 in $N_{c}$ and a significant increase to 7.5 in the $N_{w}$ case. While the mean northern component of the BI value in the CTRL 
and NNR are in agreement, significant changes occur toward a weaker subtropical jet for $N_{c}$ and a strengthening of the jet in $N_{w}$ (Fig. 7b). The imposed surface heating/cooling leads to a modification in the upperlevel jet structure through changes in the baroclinicity and thermal wind arguments. The simulation of the midlatitude slowdown as measured by the middle component of the BI is improved for the $N_{w}$ case with a mean value of 29.6 and worsened for $N_{c}$ with a mean of 37.7 (relative to 21.2 and 33.0 for NNR and CTRL, respectively; Fig. 7c). For the southern component of the BI, $N_{c}$ and CTRL cases do not differ significantly from NNR (Fig. 7d). In contrast, $N_{w}$ exhibits a significant reduction in the strength of the polar front jet. As before, the variability in the modeled $\mathrm{BI}$ for any of the components does not differ from that in NNR with the exception of a significantly enhanced variability in the $\mathrm{N}_{w}$ case compared to NNR for the southern component (Fig. 7d).

Anomalies in the geopotential height field at the $500-\mathrm{hPa}$ level in the simulations with changed tropical heating $\left(N_{w}\right.$ and $\left.N_{c}\right)$ relative to the CTRL are shown in Fig. 8. The tropical heating in the $N_{w}$ case acts as a source for atmospheric Rossby waves, with a southeastward trajectory over eastern Australia/New Zealand toward the southeast Pacific (Fig. 8a): negative height anomalies center over the Tasman Sea and Tasmania extending toward the southwest, while positive anomalies in excess of $70 \mathrm{~m}$ are located over the southwestern Pacific over the latitude band $50^{\circ}-70^{\circ} \mathrm{S}$. The height anomalies of a similar Rossby wave train are of opposite sign for the $N_{c}$ simulation (Fig. $8 \mathrm{~b}$ ). While the magnitudes of the height anomalies in $N_{c}$ are slightly reduced compared to $N_{w}$, the overall response is remarkably symmetric between the two cases. The location and sign of the height anomalies associated with the Rossby wave train at $40^{\circ}-50^{\circ} \mathrm{S}$ contribute toward a weakened westerly flow for the $N_{w}$ case and an enhancement of the zonal flow for $N_{c}$ in the Australia-New Zealand sector. This slowdown in the zonal flow at midlatitudes is recorded in the middle component of the BI in $N_{w}$, compared to higher mid-BI values for the $N_{c}$ case (Fig. 7c). The reduction in blocking activity in the $N_{c}$ case is consistent with Renwick and Revell (1999), who found El Niño events, associated with anomalous cool SST to the north of Australia, to be characterized by reduced blocking in the New Zealand sector. Small variations in the alignment/ position of the strong gradient in height anomalies south of $50^{\circ} \mathrm{S}$ (Fig. 8a) as part of the Rossby wave train could account for the increased variability seen in the southern component of the BI in the $N_{w}$ case (Fig. $7 \mathrm{~d}$ ). In contrast, the gradient in height anomalies is weaker in $N_{c}$ (Fig. 8b) and variability in the southern component of the $\mathrm{BI}$ is less pronounced (Fig. 7d).

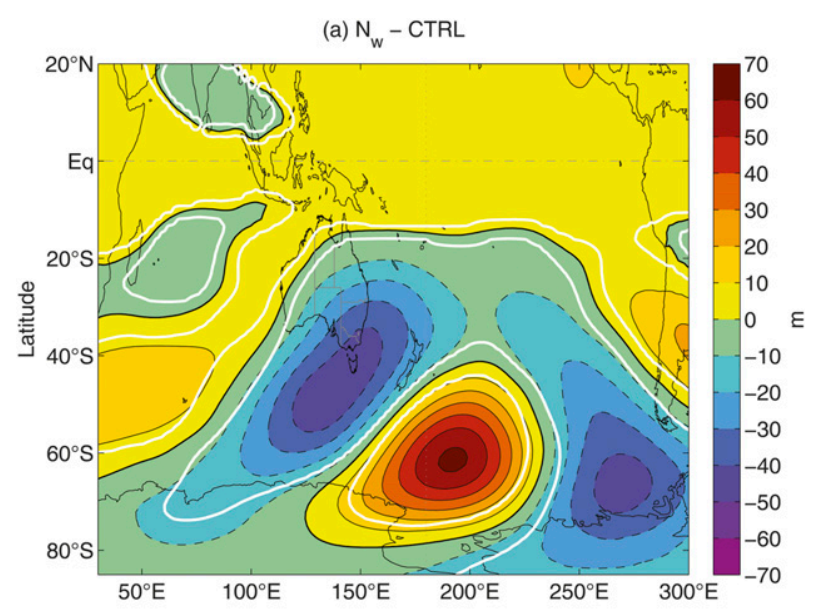

(b) $\mathrm{N}_{\mathrm{c}}-\mathrm{CTRL}$

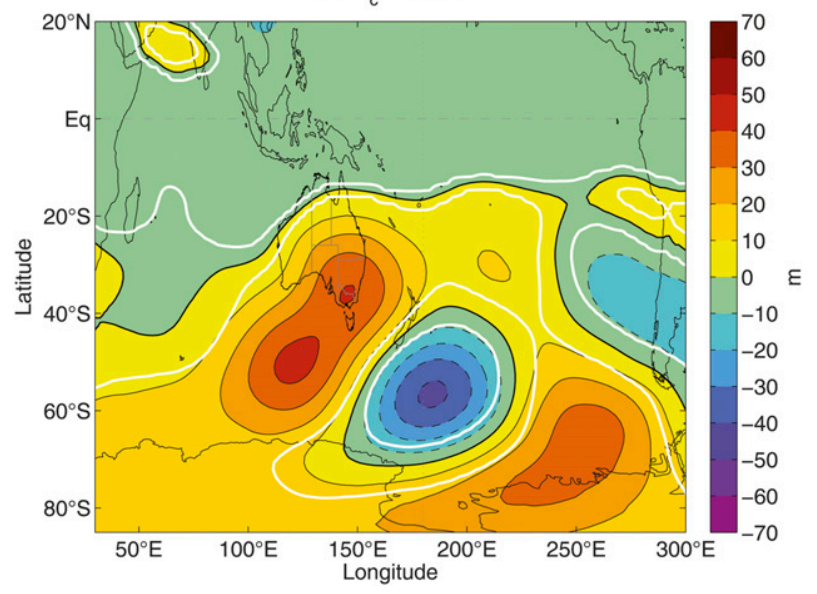

FIG. 8. Geopotential height anomaly (m) at $500 \mathrm{hPa}$ during JJA of the (a) $N_{w}$ and (b) $N_{c}$ experiment relative to the CTRL, with significant anomalies at the $95 \%$ level delimited by the white contour.

\section{b. Western Indian Ocean SST}

The role of anomalous SST in the western Indian Ocean for Australian climate has been raised previously as a means of transmitting ENSO and Indian Ocean dipole impacts onto extratropical Australian rainfall, mediated through Rossby wave trains (Cai et al. 2011). Here, we explore the effect of western Indian Ocean SST on Rossby wave trains and blocking in the AustraliaNew Zealand sector further: in the 100-yr simulations $\mathrm{WIO}_{w}$ and $\mathrm{WIO}_{c}$, warm/cold SST anomalies were superimposed over the western Indian Ocean within $5^{\circ} \mathrm{N}-$ $12^{\circ} \mathrm{S}, 40^{\circ}-90^{\circ} \mathrm{E}$ (Fig. 1, Table 1).

Figures 9a,b shows the anomalous geopotential height field at the 500-hPa level during JJA in the $\mathrm{WIO}_{w}$ and $\mathrm{WIO}_{c}$ experiments relative to the CTRL. While considerably weaker than for the $N_{w}$ and $N_{c}$ cases (Fig. 8), the geopotential height anomalies are suggestive of a Rossby wave train emanating from the western Indian Ocean for both $\mathrm{WIO}_{w}$ and $\mathrm{WIO}_{c}$ (Figs. 9a,b). Interestingly, the path 

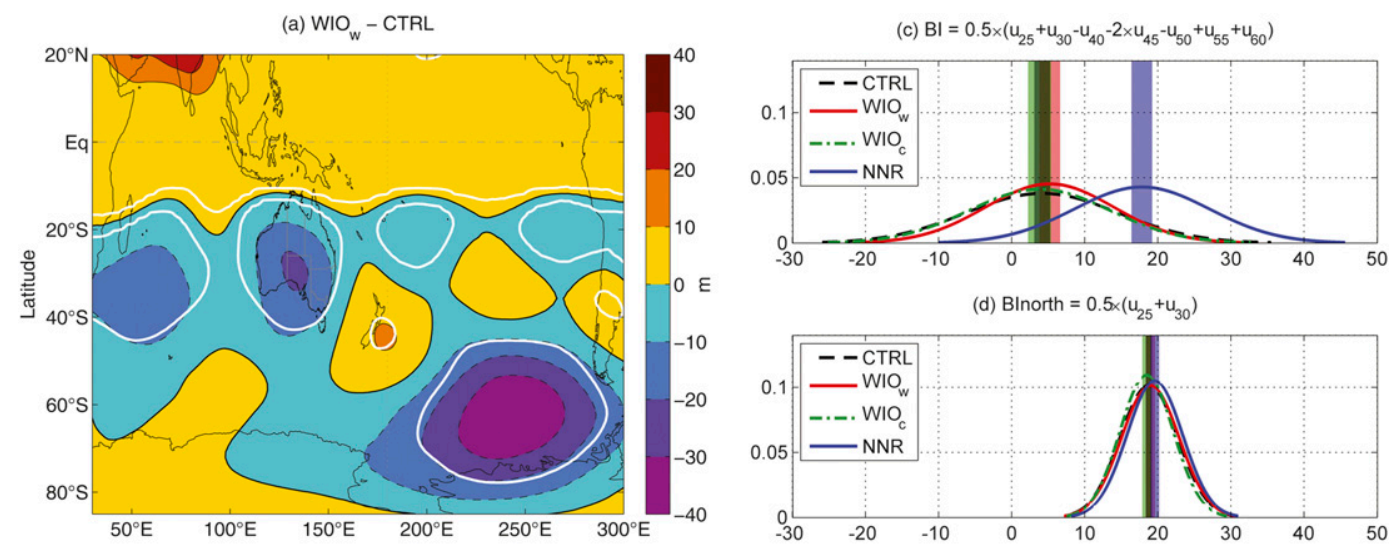

(b) WIO - CTRL

(e) - BImid $=0.5 \times\left(u_{40}+2 \times u_{45}+u_{50}\right)$
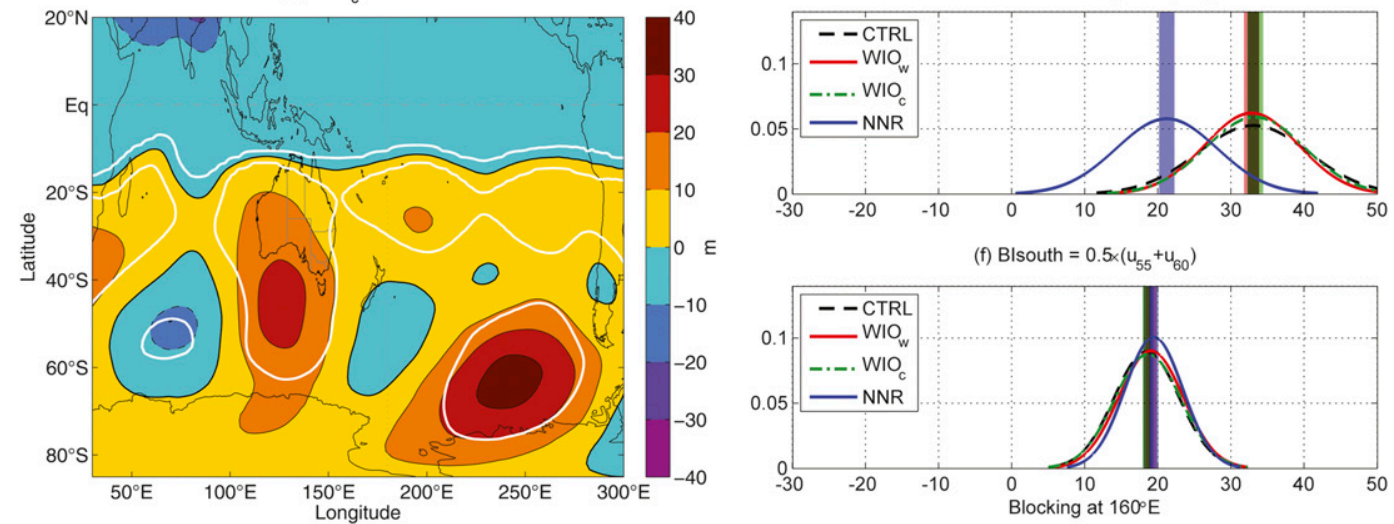

FIG. 9. Geopotential height anomaly (m) at $500 \mathrm{hPa}$ during JJA of the (a) $\mathrm{WIO}_{w}$ and (b) $\mathrm{WIO}_{c}$ experiment relative to the CTRL, with significant anomalies at the $95 \%$ level delimited by the white contour. Fitted distribution of JJA blocking index at $160^{\circ} \mathrm{E}$ from reanalysis and model experiments for NNR (blue), CTRL (black), WIO ${ }_{w}$ (red), and $\mathrm{WIO}_{c}$ (green) for the index components: (c) total, (d) north, (e) middle, and (f) south. Shading in (c)-(f) indicates the $95 \%$ confidence interval of the mean BI for the respective distributions.

of the Rossby wave train in the $\mathrm{WIO}_{w}$ and $\mathrm{WIO}_{c}$ cases is not symmetric, with a more northward displaced trajectory for $\mathrm{WIO}_{w}$, compared to $\mathrm{WIO}_{c}$. The positive/ negative geopotential height anomalies in the $\mathrm{WIO}_{w}$ experiment center over Southern Australia and New Zealand, respectively (Fig. 9a), while those of opposite sign in $\mathrm{WIO}_{c}$ pass to the south of Australia and New Zealand (Fig. 9b). The distribution of the total BI during JJA only indicates a slight, though not significant, improvement for the $\mathrm{WIO}_{w}$ case compared to the CTRL (Fig. 9c). The distribution of none of the BI components in the $\mathrm{WIO}_{w}$ and $\mathrm{WIO}_{c}$ experiments differs significantly from the CTRL (Figs. 9c-f).

These AGCM experiments seem to indicate that western Indian Ocean SSTs are not crucial in varying Australian climate, as seen mediated through the Rossby wave train in observations (Cai et al. 2011). The emphasis on eastern Indian Ocean SST, as included in the $N_{w} / N_{c}$ cases, instead agrees with Ummenhofer et al.
(2009), who showed that rainfall across southern regions of Australia is modulated by the meridional gradient in eastern Indian Ocean SST, with little effect in response to western Indian Ocean SST anomalies. It therefore appears that, in addition to the magnitude, the exact location of the centers of the geopotential height anomalies is crucial for the impact on blocking: a slight shift in the Rossby wave train path due to a shift in the location of heating/cooling along the equator greatly modifies the effect on blocking in the Australia-New Zealand sector, as seen for the $N_{w} / N_{c}$ cases compared to $\mathrm{WIO}_{w} / \mathrm{WIO}_{c}$ (cf. Figs. 7-9).

\section{Combined effects for maximizing blocking}

The combined effects of tropical heating and extratropical temperature gradients are explored in a configuration that is favorable for blocking and one that is unfavorable for the Australia-New Zealand sector 
(a) $\mathrm{BI}=0.5 \times\left(\mathrm{u}_{25}+\mathrm{u}_{30}-\mathrm{u}_{40}-2 \times \mathrm{u}_{45}-\mathrm{u}_{50}+\mathrm{u}_{55}+\mathrm{u}_{60}\right)$

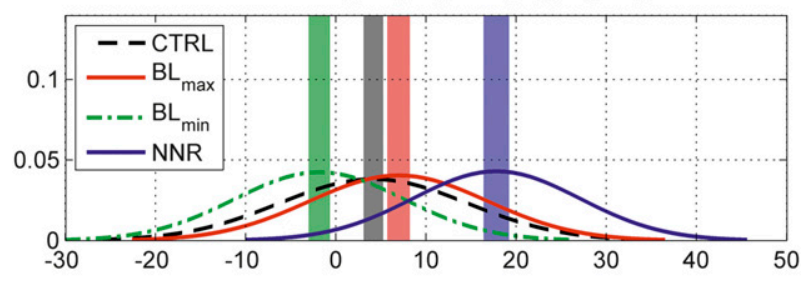

(b) BInorth $=0.5 \times\left(u_{25}+u_{30}\right)$

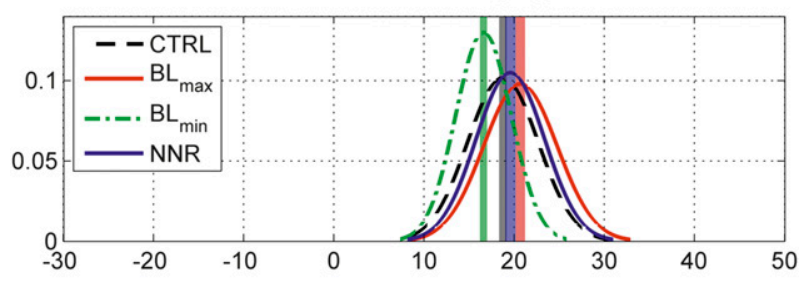

(c) - BImid $=0.5 \times\left(u_{40}+2 \times u_{45}+u_{50}\right)$

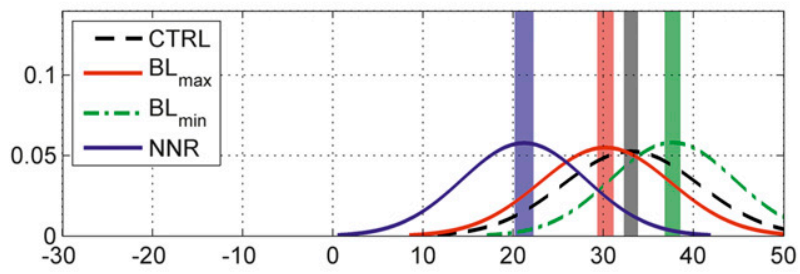

(d) Blsouth $=0.5 \times\left(u_{55}+u_{60}\right)$

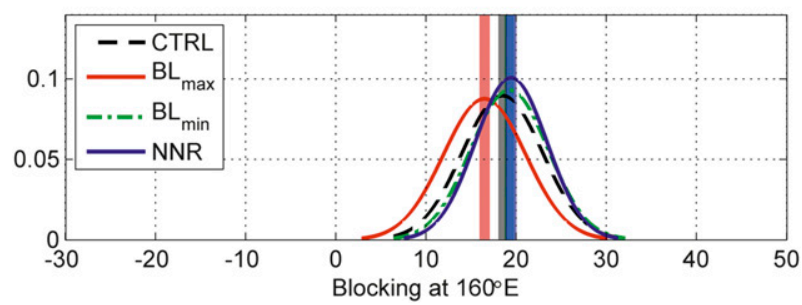

FIG. 10. As in Fig. 6, but for a blocking-favorable/unfavorable configuration for $\mathrm{BL}_{\max }$ (red) and $\mathrm{BL}_{\min }$ (green).

(Fig. 10). As such, $\mathrm{BL}_{\max }$ is characterized by anomalous warm SST to the north of Australia, cold land temperatures over southern Australia, and cold (warm) SST anomalies to the southwest (southeast) of Australia (cf. Table 1, Fig. 11a). In $\mathrm{BL}_{\min }$, the opposite configuration is employed (Fig. 11b).

The fitted distributions to the BI during JJA are given in Fig. 10 for the combined configurations maximizing/ minimizing the blocking, as well as CTRL and NNR for reference. The mean value of the total $\mathrm{BI}$ in the $\mathrm{BL}_{\max }$ (7.0) and $\mathrm{BL}_{\min }(-1.8)$ case differ significantly from the CTRL (4.2; Fig. 10a). In particular, the $\mathrm{BI}$ in $\mathrm{BL}_{\min }$ is reduced relative to the CTRL and NNR. This is also apparent for the northern component, where a mean BI of 16.6 for $\mathrm{BL}_{\min }$ significantly underestimates the NNR value of 19.6 and the CTRL at 18.7 (Fig. 10b), as it does the year-to-year variability. On the other hand, the (a) BLmax

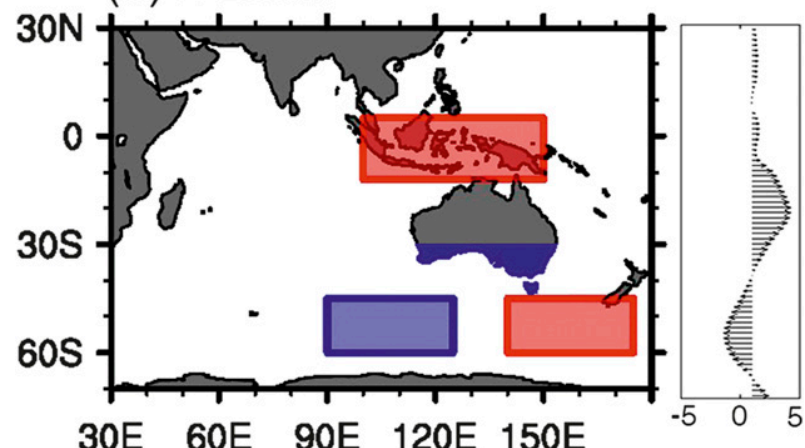

(b) BLmin

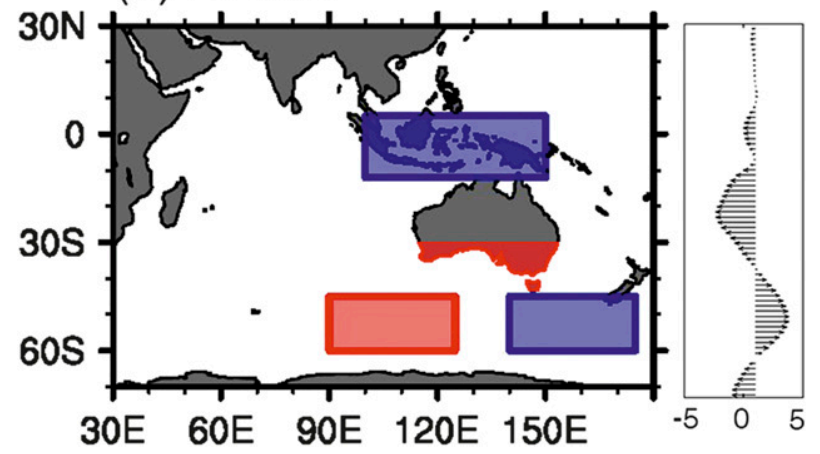

FIG. 11. Schematic of surface temperature anomalies employed and resultant $500-\mathrm{hPa}$ zonal wind anomalies $\left(\mathrm{m} \mathrm{s}^{-1}\right)$ at $160^{\circ} \mathrm{E}$ in the experiments for the (a) $\mathrm{BL}_{\max }$ and (b) $\mathrm{BL}_{\min }$ case. Zonal wind anomalies are relative to the CTRL.

mean $\mathrm{BI}$ of 20.7 in $\mathrm{BL}_{\max }$ indicates a significant strengthening of the subtropical jet relative to the CTRL, again through surface heating modifying the upper-level jet structure through thermal wind arguments and changing baroclinicity, to be consistent with the observed values in NNR. The slowdown in midlatitudes seen in NNR with a mean value of 21.2 is better reproduced in $\mathrm{BL}_{\max }$ (30.2) than in the CTRL (33.0; Fig. $10 \mathrm{c}) . \mathrm{BL}_{\min }$ with a mean value of 37.7 for the mid-BI component indicates significantly stronger zonal flow and little slowdown compared to the other experiments. For the southern components, only $\mathrm{BL}_{\max }$ records a significant change in the polar jet compared to the other cases, with a reduction in the strength of the polar jet compared to NNR and CTRL (Fig. 10d). The weakening of the polar jet in $\mathrm{BL}_{\max }$ represents a negative impact of warm SST north of Australia on the southern component of the BI. However, this is outweighed by the positive effects on the northern and mid-BI components to result in a significant overall improved total $\mathrm{BI}$ in $\mathrm{BL}_{\max }$ compared to any of the other experiments conducted here. 


\section{Conclusions}

This study explored characteristics of $\mathrm{SH}$ atmospheric blocking in AGCM simulations using the NCAR CAM3 model with particular emphasis on the area of preferred SH blocking (Taljaard 1972): the Australia-New Zealand sector. Previous work highlighted that blocking characteristics are determined both by the structure of the mean flow, as well as the interaction with disturbances on the mean structure acting across a range of time scales. We thus first focused on diagnosing model deficiencies in mean zonal flow characteristics and their relation to blocking in CAM3.

The SH midlatitude zonal flow in the model is overestimated and does not capture the observed wintertime split-flow structure over the Australia-New Zealand sector (Fig. 2), considered to be crucial for blocking in the region (e.g., van Loon 1956; Taljaard 1972; Trenberth and Mo 1985). As an indicator for blocking, we used the Australian-region-focused blocking index (BI) described by Pook and Gibson (1999), characterized by a northern component indicative of the strength of the subtropical jet, a middle component reflecting the slowdown of zonal flow at midlatitudes, and a southern component measuring the magnitude of the polar front jet. The model broadly captures the maximum location centered at $180^{\circ}$ and predominant season of enhanced wintertime blocking (Fig. 3). However, the blocking magnitude is severely underestimated throughout the year, but particularly during late winter and early spring, due largely to an underestimation in the midlatitude slowdown of the zonal flow. In contrast, the variability of the BI in the model is comparable to observed (Fig. 4). This realistic simulation of blocking variability echoes earlier results (Scaife et al. 2010, 2011): that it is the more realistic representation of the mean state at higher resolution that relates to improved blocking activity in models, not necessarily the better upscale maintenance of blocking structures through resolved small-scale eddies.

Furthermore, using a series of AGCM sensitivity experiments we evaluated the role of surface forcing in providing anomalous disturbances to the mean flow field to a range of factors proposed previously and related in varying degrees to the broad "warm-ocean/cold-land anomaly pattern...linked to a dynamical environment favorable for blocking" (Haekkinen et al. 2011). These factors generating a warm-ocean/cold-land anomaly pattern included 1) tropical SST north of Australia, 2) extratropical SST to the south, 3) anomalous land temperatures across the Australian continent, and 4) a combination thereof.

The observed SST during the year 1989, which was characterized in observations by record high wintertime
BI (Pook et al. 2013) and strong split flow in the Australia-New Zealand sector (Bals-Elsholz et al. 2001), featured several of the above factors and were used to force the AGCM (Fig. 5). The JJA BI in the 1989 simulation indicates enhanced blocking relative to the control owing to a better representation of the midlatitude slowdown of the zonal flow. The various factors in surface forcing, partially inherent in the 1989 SST and proposed to affect blocking, were then systematically assessed in idealized AGCM sensitivity experiments, both individually and in combination.

For this, Fig. 11 highlights changed surface forcing in a blocking-favorable and blocking-unfavorable configuration, respectively, along with a schematic representation of the underlying mechanisms. The BI in the experiments with changed extratropical temperature gradients in the most $\left(L_{c}+\mathrm{SW}_{c}+\mathrm{SE}_{w}\right)$ and least $\left(L_{w}+\mathrm{SW}_{w}+\mathrm{SE}_{c}\right)$ blocking-favorable configuration did not differ significantly from the control (Fig. 6). It appears that the effect of extratropical surface forcing via changes in anticyclonicity and thermal wind on midlatitude zonal flow is minimal. In contrast, tropical heating/cooling to the north of Australia affects the strength of the subtropical jet through thermal wind arguments and changes in baroclinicity, resulting in a strengthened/weakened subtropical jet, respectively (Fig. 7). Furthermore, changes in the slowdown in midlatitudes are mediated through Rossby wave interaction (Fig. 8), with warm SST anomalies north of Australia associated with enhanced anticyclonicity in the Tasman Sea region and reduced midlatitude flow, while the opposite occurs for cool North Australian SST (Fig. 11). The blocking activity in the configurations maximizing/minimizing blocking (Fig. 10) is largely indistinguishable from that in the tropical heating/cooling experiments (Fig. 7), respectively. In addition to an enhanced meridional pressure gradient and overly strong zonal flow in GCMs, these results emphasize the role of remote biases in tropical convection for a realistic representation of midlatitude blocking activity: anomalously weak tropical convection over the Maritime Continent can result in systematic underestimates of extratropical blocking activity in GCMs, as shown previously for the North Pacific (Ferranti et al. 1994; Hinton et al. 2009).

A better understanding of factors influencing $\mathrm{SH}$ blocking characteristics is desirable, even more so in light of strengthened westerlies due to a robust upward trend in the southern annular mode (e.g., Thompson and Solomon 2002), a weakening of the split jet in the region in recent decades (Bals-Elsholz et al. 2001), reduced blocking activity (Risbey et al. 2013), and decreases in cutoff low rainfall across southern regions of Australia 
(Pook et al. 2009; Risbey et al. 2013). To usefully assess future projected changes in midlatitude blocking and, by inference, rainfall projections in those regions where blocking is an important driver, improvement in the representation of atmospheric blocking in state-of-theart GCMs is thus crucial, especially given that blocking can be considered an "emergent phenomenon created indirectly by dynamical and physical processes in the model... [making] blocking a useful test of the ability of the model to represent the atmosphere" (Hinton et al. 2009).

Acknowledgments. NCEP-NCAR reanalysis products were provided by NOAA/OAR/ESRL PSD, Boulder, Colorado, United States, through their website http://www.cdc.noaa.gov; ERA-40 data were provided by the European Centre for Medium-Range Weather Forecasting; and Hadley Centre HadISST data were provided by the U.K. Met Office. Use of the NCAR CCSM3 for the model simulations is gratefully acknowledged. The simulations were undertaken on the NCI National Facility in Canberra, Australia, which is supported by the Australian Commonwealth Government. The manuscript benefited from helpful suggestions by Andrew Marshall and Tim Cowan. C.C.U. received support from the Australian Research Council through funding awarded to the Centre of Excellence for Climate System Science and the Penzance Endowed Fund at WHOI. P.C.M., M.J.P., and J.S.R. were funded by the CSIRO Climate Adaptation Flagship and the Managing Climate Variability R\&D Program.

\section{REFERENCES}

Bals-Elsholz, T. M., E. H. Atallah, L. F. Bosart, T. A. Wasula, M. J. Cempa, and A. R. Lupo, 2001: The wintertime Southern Hemisphere split jet: Structure, variability and evolution. J. Climate, 14, 4191-4215.

Berrisford, P., B. J. Hoskins, and E. Tyrlis, 2007: Blocking and Rossby wave breaking on the dynamical tropopause in the Southern Hemisphere. J. Atmos. Sci., 64, 2881-2898.

Cai, W., P. van Rensch, T. Cowan, and H. H. Hendon, 2011: Teleconnection pathways of ENSO and the IOD and the mechanisms for impacts on Australian rainfall. J. Climate, 24, 3910-3923.

Campatella, C. M., and N. E. Possia, 2007: Upper-level cut-off lows in southern South America. Meteor. Atmos. Phys., 96, 181-191.

Collins, W. D., and Coauthors, 2006a: The Community Climate System Model version 3 (CCSM3). J. Climate, 19, 2122-2143.

— , and Coauthors, 2006b: The formulation and atmospheric simulation of the Community Atmosphere Model Version 3 (CAM3). J. Climate, 19, 2144-2161.

Coumou, D., and S. Rahmstorf, 2012: A decade of weather extremes. Nat. Climate Change, 2, 491-496.

Croci-Maspoli, M., C. Schwierz, and H. C. Davies, 2007: A multifaceted climatology of atmospheric blocking and its recent linear trend. J. Climate, 20, 633-649.
Deser, C., A. Capotondi, R. Saravanan, and A. S. Phillips, 2006: Tropical Pacific and Atlantic climate variability in CCSM3. J. Climate, 19, 2451-2481.

Ferranti, L., F. Molteni, and T. N. Palmer, 1994: Impact of localized tropical and extratropical SST anomalies in ensembles of seasonal GCM integrations. Quart. J. Roy. Meteor. Soc., 120, 1613-1645.

Fuenzalida, H. A., R. Sánchez, and R. D. Garreaud, 2005: A climatology of cutoff lows in the Southern Hemisphere. J. Geophys. Res., 110, D18101, doi:10.1029/2005JD005934.

Graff, L. S., and J. H. LaCasce, 2012: Changes in the extratropical storm tracks in response to changes in SST in an AGCM. J. Climate, 25, 1854-1870.

Grose, M. R., M. J. Pook, P. C. McIntosh, J. S. Risbey, and N. L. Bindoff, 2012: The simulation of cutoff lows in a regional climate model: Reliability and future trends. Climate Dyn., 39, $445-459$.

Hack, J. J., J. M. Caron, G. Danabasoglu, K. W. Oleson, C. Bitz, and J. E. Truesdale, 2006a: CCSM-CAM3 climate simulation sensitivity to changes in horizontal resolution. J. Climate, 19, 2267-2289.

,-- S. M. Yeager, K. W. Oleson, M. M. Holland, J. E. Truesdale, and P. J. Rasch, 2006b: Simulation of the global hydrological cycle in the CCSM Community Atmosphere Model version 3 (CAM3): Mean features. J. Climate, 19, 2199 2221.

Haekkinen, S., P. B. Rhines, and D. L. Worthen, 2011: Atmospheric blocking and Atlantic multidecadal ocean variability. Science, 334, 655-659.

Hinton, T. J., B. J. Hoskins, and G. M. Martin, 2009: The influence of tropical sea surface temperatures and precipitation on North Pacific atmospheric blocking. Climate Dyn., 33, 549563.

Hudson, D., A. G. Marshall, and O. Alves, 2011: Intraseasonal forecasting of the 2009 summer and winter Australian heat waves using POAMA. Wea. Forecasting, 26, 257-279.

Hurrell, J. W., J. J. Hack, A. S. Phillips, J. Caron, and J. Yin, 2006: The dynamical simulation of the Community Atmosphere Model version 3 (CAM3). J. Climate, 19, 21622183.

—_ - D. D. Shea, J. M. Caron, and J. Rosinski, 2008: A new sea surface temperature and sea ice boundary dataset for the Community Atmosphere Model. J. Climate, 21, 51455153.

Kaas, E., and G. Branstator, 1993: The relationship between a zonal index and blocking activity. J. Atmos. Sci., 50, 30613077.

Kalnay, E., and Coauthors, 1996: The NCEP/NCAR 40-Year Reanalysis Project. Bull. Amer. Meteor. Soc., 77, 437-471.

Kistler, R., and Coauthors, 2001: The NCEP-NCAR 50-Year Reanalysis: Monthly means CD-ROM and documentation. Bull. Amer. Meteor. Soc., 82, 247-267.

Kug, J.-S., and F.-F. Jin, 2009: Left-hand rule for synoptic eddy feedback on low-frequency flow. Geophys. Res. Lett., 36, L05709, doi:10.1029/2008GL036435.

Lau, N.-C., 1988: Variability of the observed midlatitude storm tracks in relation to low-frequency changes in the circulation pattern. J. Atmos. Sci., 45, 2718-2743.

Lupo, A. R., and P. J. Smith, 1995: Climatological features of blocking anticyclones in the Northern Hemisphere. Tellus, 47, 439-456.

Matsueda, M., H. Endo, and R. Mizuta, 2010: Future change in Southern Hemisphere summertime and wintertime 
atmospheric blockings simulated using a 20-km-mesh AGCM. Geophys. Res. Lett., 37, L02803, doi:10.1029/2009GL041758.

McIntosh, P. C., M. J. Pook, J. S. Risbey, and C. Ummenhofer, 2008: Do climate models get the weather systems right? Proc. 15th National Australian Meteorological and Oceanographic Society Conf., Geelong, VIC, Australia, AMOS, 101. [Available online at http://www.amos.org.au/sitebuilder/publications/ knowledge/asset/files/7/amosabstractsandcover.pdf.]

Meyers, G., P. McIntosh, L. Pigot, and M. Pook, 2007: The years of El Niño, La Niña, and interactions with the tropical Indian Ocean. J. Climate, 20, 2872-2880.

Neale, R., J. Richter, S. Park, P. Lauritzen, S. Vavrus, P. Rasch, and M. Zhang, 2013: The mean climate of the Community Atmosphere Model (CAM4) in forced SST and fully coupled experiments. J. Climate, 26, 5150-5168.

Noar, P. F., 1983: Numerical modelling of blocking, with reference to June 1982. Aust. Meteor. Mag., 31, 37-49.

Ogawa, F., H. Nakamura, K. Nishii, T. Miyasaka, and A. KuwanoYoshida, 2012: Dependence of the climatological axial latitudes of the tropospheric westerlies and storm tracks on the latitude of an extratropical oceanic front. Geophys. Res. Lett., 39, L05804, doi:10.1029/2011GL049922.

Pezza, A. B., P. Van Rensch, and W. Cai, 2012: Severe heat waves in southern Australia: Synoptic climatology and large scale connections. Climate Dyn., 38, 209-224.

Pook, M., 1994: Atmospheric blocking in the Australasian region in the Southern Hemisphere winter. Ph.D. thesis, University of Tasmania, $168 \mathrm{pp}$.

_ , and T. Gibson, 1999: Atmospheric blocking and storm tracks during SOP-1 of the FROST Project. Aust. Meteor. Mag., Special Edition, 51-60.

_ P. C. McIntosh, and G. A. Meyers, 2006: The synoptic decomposition of cool season rainfall in the southeastern Australian cropping region. J. Appl. Meteor. Climatol., 45, 1156-1170.

- - S. Lisson, J. Risbey, C. C. Ummenhofer, P. McIntosh, and M. Rebbeck, 2009: The autumn break for cropping in southeast Australia: Trends, synoptic influences and impacts on yield. Int. J. Climatol., 29, 2012-2026.

_ J. S. Risbey, P. C. McIntosh, C. C. Ummenhofer, A. Marshall, and G. A. Meyers, 2013: The seasonal cycle of blocking and associated physical mechanisms in the Australian region and relationship with rainfall. Mon. Wea. Rev., in press.

Rayner, N. A., D. E. Parker, E. B. Horton, C. K. Folland, L. V. Alexander, and D. P. Rowell, 2003: Global analyses of SST, sea ice and night marine air temperature since the late nineteenth century. J. Geophys. Res., 108, 4407, doi:10.1029/ 2002JD002670.

Reboita, M. S., R. Nieto, L. Gimeno, R. P. da Rocha, T. Ambrizzi, R. Garreaud, and L. F. Krüger, 2010: Climatological features of cutoff low systems in the Southern Hemisphere. J. Geophys. Res., 115, D17104, doi:10.1029/2009JD013251.

Renwick, J. A., 1998: ENSO-related variability in the frequency of South Pacific blocking. Mon. Wea. Rev., 126, 3117-3123.

—_ and J. M. Wallace, 1996: Relationships between North Pacific wintertime blocking, El Nino, and the PNA pattern. Mon. Wea. Rev., 124, 2071-2076.

—_, and M. J. Revell, 1999: Blocking over the South Pacific and Rossby wave propagation. Mon. Wea. Rev., 127, 2233 2247.

Ringer, M. A., and Coauthors, 2006: The physical properties of the atmosphere in the new Hadley Centre Global Environmental Model (HadGEM1). Part II: Aspects of variability and regional climate. J. Climate, 19, 1302-1326.
Risbey, J. S., M. J. Pook, P. C. McIntosh, M. C. Wheeler, and H. H. Hendon, 2009: On the remote drivers of rainfall variability in Australia. Mon. Wea. Rev., 137, 3233-3253.

— , P. C. McIntosh, and M. J. Pook, 2013: Synoptic components of rainfall variability and trends in southeast Australia. Int. J. Climatol., doi:10.1002/joc.3597, in press.

Scaife, A. A., and Coauthors, 2011: Improved Atlantic winter blocking in a climate model. Geophys. Res. Lett., 38, L23703, doi:10.1029/2011GL049573.

- T. Woollings, J. Knight, G. Martin, and T. Hinton, 2010: Atmospheric blocking and mean biases in climate models. J. Climate, 23, 6143-6152.

Shutts, G. J., 1986: A case study of eddy forcing during an Atlantic blocking episode. Advances in Geophysics, Vol. 29, Academic Press, 135-162.

Sillmann, J., and M. Croci-Maspoli, 2009: Present and future atmospheric blocking and its impact on European mean and extreme climate. Geophys. Res. Lett., 36, L10702, doi:10.1029/ 2009GL038259.

Simpson, R. W., and W. K. Downey, 1975: The effect of a warm mid-latitude sea surface temperature anomaly on a numerical simulation of the general circulation of the Southern Hemisphere. Quart. J. Roy. Meteor. Soc., 101, 847-867.

Singleton, A. T., and C. J. C. Reason, 2007: A numerical study of an intense cutoff low pressure system over South Africa. Mon. Wea. Rev., 135, 1128-1150.

Smith, T. M., and R. W. Reynolds, 2003: Extended reconstruction of global sea surface temperatures based on COADS data (1854-1997). J. Climate, 16, 1495-1510.

, and - 2004: Improved extended reconstruction of SST (1854-1997). J. Climate, 17, 2466-2477.

Taljaard, J. J., 1972: Synoptic meteorology of the Southern Hemisphere. Meteorology of the Southern Hemisphere, D. J. Karoly and D. G. Vincent, Eds., Amer. Meteor. Soc., 139-211.

Thompson, D. W. J., and S. Solomon, 2002: Interpretation of recent Southern Hemisphere climate change. Science, 296, 895899.

Tibaldi, S., and F. Molteni, 1990: On the operational predictability of blocking. Tellus, 42A, 343-365.

_ E. Tosi, A. Navarra, and L. Pedulli, 1994: Northern and Southern Hemisphere seasonal variability of blocking frequency and predictability. Mon. Wea. Rev., 122, 1971-2003.

, F. D'Andrea, E. Tosi, and E. Roeckner, 1997: Climatology of Northern Hemisphere blocking in the ECHAM model. Climate Dyn., 13, 649-666.

Timbal, B., and H. Hendon, 2011: The role of tropical modes of variability in recent rainfall deficits across the MurrayDarling basin. Water Resour. Res., 47, W00G09, doi:10.1029/ 2010WR009834.

Trenberth, K. E., and K. Mo, 1985: Blocking in the Southern Hemisphere. Mon. Wea. Rev., 113, 3-21.

Ummenhofer, C. C., A. Sen Gupta, M. J. Pook, and M. H. England, 2008: Anomalous rainfall over southwest Western Australia forced by Indian Ocean sea surface temperatures. J. Climate, 21, 5113-5134.

,,-- A. S. Taschetto, and M. H. England, 2009: Modulation of Australian precipitation by meridional gradients in east Indian Ocean sea surface temperature. J. Climate, 22, 55975610.

Uppala, S. M., and Coauthors, 2005: The ERA-40 Re-Analysis. Quart. J. Roy. Meteor. Soc., 131, 2961-3012.

van Loon, H., 1956: Blocking action in the Southern Hemisphere. Notos, 5, 117-119. 
Vial, J., and T. J. Osborn, 2012: Assessment of atmosphere-ocean general circulation model simulations of winter Northern Hemisphere atmospheric blocking. Climate Dyn., 39, 95-112.

Walsh, K., 1994: On the influence of the Andes on the general circulation of the Southern Hemisphere. J. Climate, 7, 10191025.

Woollings, T., B. Hoskins, M. Blackburn, D. Hassell, and K. Hodges, 2010: Storm track sensitivity to sea surface temperature resolution in a regional atmosphere model. Climate Dyn., 35, 341-353.
Wright, A. D. F., 1974: Blocking action in the Australian region. Tech. Rep. 10, Bureau of Meteorology, Melbourne, Australia, $29 \mathrm{pp}$.

Zelle, H., G. J. van Oldenborgh, G. Burgers, and H. Dijkstra, 2005: El Niño and greenhouse warming: Results from ensemble simulations with the NCAR CCSM. J. Climate, 18, 4669-4683.

Zidikheri, M. J., J. S. Frederiksen, and T. J. O'Kane, 2007: Multiple equilibria and atmospheric blocking. Frontiers in Turbulence and Coherent Structures, J. Denier and J. S. Frederiksen, Eds., World Scientific, 59-85. 